\title{
Advancing a Model-Validated Statistical Method for Decomposing the Key Oceanic Drivers of Regional Climate: Focus on Northern and Tropical African Climate Variability in the Community Earth System Model (CESM) $\mathscr{O}$
}

\author{
Fuyao Wang, Yan Yu, AND Michael Notaro \\ Nelson Institute Center for Climatic Research, University of Wisconsin-Madison, Madison, Wisconsin \\ JIAFU MAO, XIAOYING SHI, AND YAXING WEI \\ Environmental Sciences Division, and Climate Change Science Institute, Oak Ridge National Laboratory, \\ Oak Ridge, Tennessee
}

(Manuscript received 3 April 2017, in final form 14 July 2017)

\begin{abstract}
This study advances the practicality and stability of the traditional multivariate statistical method, generalized equilibrium feedback assessment (GEFA), for decomposing the key oceanic drivers of regional atmospheric variability, especially when available data records are short. An advanced stepwise GEFA methodology is introduced, in which unimportant forcings within the forcing matrix are eliminated through stepwise selection. Method validation of stepwise GEFA is performed using the CESM, with a focused application to northern and tropical Africa (NTA). First, a statistical assessment of the atmospheric response to each primary oceanic forcing is carried out by applying stepwise GEFA to a fully coupled control run. Then, a dynamical assessment of the atmospheric response to individual oceanic forcings is performed through ensemble experiments by imposing sea surface temperature anomalies over focal ocean basins. Finally, to quantify the reliability of stepwise GEFA, the statistical assessment is evaluated against the dynamical assessment in terms of four metrics: the percentage of grid cells with consistent response sign, the spatial correlation of atmospheric response patterns, the area-averaged seasonal cycle of response magnitude, and consistency in associated mechanisms between assessments. In CESM, tropical modes, namely El NiñoSouthern Oscillation and the tropical Indian Ocean Basin, tropical Indian Ocean dipole, and tropical Atlantic Niño modes, are the dominant oceanic controls of NTA climate. In complementary studies, stepwise GEFA is validated in terms of isolating terrestrial forcings on the atmosphere, and observed oceanic and terrestrial drivers of NTA climate are extracted to establish an observational benchmark for subsequent coupled model evaluation and development of process-based weights for regional climate projections.
\end{abstract}

\section{Introduction}

As the slowly varying component of the climate system, the ocean makes regional climate predictability more achievable over time scales of a season or longer (Lee and Wang 2012). Better understanding the impacts of sea surface temperature (SST) on the atmosphere is vital to attain reliable future regional climate projections. However, decomposing and understanding the key oceanic drivers of regional climate is challenging.

Supplemental information related to this paper is available at the Journals Online website: https://doi.org/10.1175/ JCLI-D-17-0219.s1.

Corresponding author: Fuyao Wang, fwang26@wisc.edu
For example, the impact of SST variability on the atmosphere is small in magnitude compared to the large atmospheric internal variability and thus difficult to detect (Liu et al. 2008). Furthermore, regional climate is influenced by both local and remote SST anomalies (Klein et al. 1999; Newman et al. 2003; Lau et al. 2006), which can interact with each other, making it difficult to separate the individual oceanic impacts on regional climate.

North-central sub-Saharan Africa $\left(10^{\circ} \mathrm{S}-20^{\circ} \mathrm{N}, 20^{\circ} \mathrm{W}-\right.$ $55^{\circ} \mathrm{E}$; Fig. 1), referred to in this paper as northern and tropical Africa (NTA) following Vizy and Cook (2012), and three subregions (Fig. 1, black boxes), namely the Sahel $\left(12^{\circ}-17^{\circ} \mathrm{N}, 20^{\circ} \mathrm{W}-40^{\circ} \mathrm{E}\right)$, the Guinea Coast (GC; $5^{\circ}-12^{\circ} \mathrm{N}, 20^{\circ} \mathrm{W}-30^{\circ} \mathrm{E}$ ), and Greater Horn of Africa (GHA; $10^{\circ} \mathrm{S}-10^{\circ} \mathrm{N}, 30^{\circ}-50^{\circ} \mathrm{E}$ ), are chosen as the study 


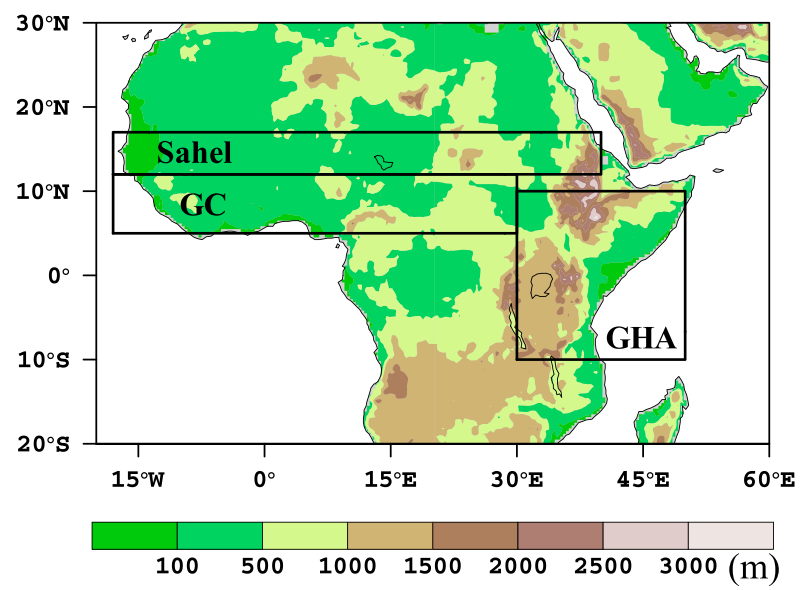

FIG. 1. Topography of Africa with three study regions: the Sahel $\left(12^{\circ}-17^{\circ} \mathrm{N}, 20^{\circ} \mathrm{W}-40^{\circ} \mathrm{E}\right)$, the Guinea Coast $\left(\mathrm{GC} ; 5^{\circ}-12^{\circ} \mathrm{N}, 20^{\circ} \mathrm{W}-30^{\circ} \mathrm{E}\right)$, and the Greater Horn of Africa $\left(\mathrm{GHA} ; 10^{\circ} \mathrm{S}-10^{\circ} \mathrm{N}, 30^{\circ}-50^{\circ} \mathrm{E}\right)$.

regions. Drought is the primary natural disaster for most African countries. Drought accounted for $25 \%$ of all natural disasters occurring in sub-Saharan Africa during 1960-2006 (Gautam 2006); compared with other natural disasters, it has substantial societal impacts (UNEP/ GRID-Arendal 2007). The effects of drought events are often exacerbated by resulting crop failure, famine, and health issues, including malaria and cholera (Few et al. 2004). The devastating drought-induced famine across the Sahel killed roughly 100000 people during the late 1960s through the early 1980s (Opio-Odongo 2014). In the 2011 East Africa drought event, millions of people were affected across the Horn of Africa (Loewenberg 2011). The Horn of Africa is currently experiencing another severe drought. According to a report from the World Food Programme (WFP 2017), 11.2 million people in the region are dealing with crisis and emergency food insecurity levels. Understanding the sources of NTA rainfall variability is crucial to gain confidence in seasonal prediction accuracy.

West African rainfall is characterized by substantial interannual (Nicholson 2013) to decadal variability (Rowell et al. 1995). On interannual time scales, previous studies have identified the impacts of El NiñoSouthern Oscillation (ENSO; Janicot et al. 2001; Joly and Voldoire 2009; Preethi et al. 2015), the Atlantic Niño (Lamb 1978; Giannini et al. 2003; Joly et al. 2007), and the Mediterranean Sea (Rowell 2003) on West African rainfall (Rodríguez-Fonseca et al. 2011, 2015, and references therein). The relationship between tropical SST anomalies and West African rainfall is not stationary (Janicot et al. 2001; Losada et al. 2012). Before the 1970s, West African rainfall was influenced mostly by tropical Atlantic SSTs, with enhanced (diminished) precipitation over the Guinea Coast (Sahel) in response to positive SST anomalies within the Gulf of Guinea. After the 1970s, the dipole rainfall response to tropical Atlantic SSTs disappeared, with negative rainfall anomalies across the entire West Africa now associated with positive tropical Pacific SST anomalies (RodríguezFonseca et al. 2011). Although previous studies applied an array of methods to separate the impact of different oceanic basins/modes on West African rainfall, there is no effective way to perform this task. A method that can quantify the different oceanic modes' influences is needed.

On decadal time scales, the general consensus is that global SST anomalies explain the persistent Sahel drought during the 1970s-1980s, and simulations in phases 3 and 5 of the Coupled Model Intercomparison Project (CMIP3 and CMIP5) forced by twentiethcentury forcings can reproduce the observed drying trend in the Sahel (Folland et al. 1986; Palmer 1986; Camberlin et al. 2001; Giannini et al. 2003; Biasutti and Giannini 2006; Rodríguez-Fonseca et al. 2015). However, modeling studies have debated the relative contribution of SST anomalies across individual ocean basins toward Sahel drought (Palmer 1986; Giannini et al. 2003; Lu and Delworth 2005; Hoerling et al. 2006; Giannini et al. 2013; Rodríguez-Fonseca et al. 2015). Such modeling study inconsistencies likely lead to the large spread in Sahel summer rainfall projections for the late twenty-first century among both CMIP3 and CMIP5 models (Rodríguez-Fonseca et al. 2015). Therefore, a deeper understanding of the oceanic drivers of West African rainfall is critically needed to reduce the spread of future hydrologic projections.

The impact of oceanic forcings on East African rainfall remains insufficiently understood. East Africa has two rain seasons, namely the long rains [March-May (MAM)] and the short rains [October-December (OND)]. Most of the CMIP coupled models cannot reproduce the observed seasonal cycle of East African precipitation, instead underestimating rainfall during long rains and overestimating rainfall during short rains (Yang et al. 2015). Short rains dominate the interannual variability in East Africa rainfall (Nicholson 2000). Some studies concluded that ENSO controls the variability of the short rains (Indeje et al. 2000; Schreck and Semazzi 2004), whereas other studies argued that tropical Indian Ocean SST plays the dominant role in modulating short rains variability (Black et al. 2003; Ummenhofer et al. 2009). The East African long rains have experienced an increase in the frequency and intensity of droughts since the 1990s (Yang et al. 2014). Although model projections from CMIP3 and CMIP5 indicate that precipitation in the long rains season will increase during the twenty-first century (Shongwe et al. 2009; Yang et al. 2014), the reliability of this projection is 
questionable since the majority of the coupled models cannot capture the observed relationship between the intensity of the long rains and SST anomalies.

To address the aforementioned challenges in extracting the impact of individual oceanic forcings on the atmosphere, a multivariate statistical method, generalized equilibrium feedback assessment (GEFA; Liu et al. 2008), is chosen for this study. GEFA can statistically separate the individual influences of different ocean basins on the atmosphere (Wen et al. 2010; Wang et al. 2013). Considering the large disagreement among modeling studies in terms of the key oceanic drivers of Sahel rainfall, an observational benchmark is needed. GEFA can be applied to either observational data or model output, and its reliability in terms of extracting the impacts of individual forcings has been demonstrated using a conceptual simple model (Liu et al. 2012a,b) and the fully coupled Community Climate System Model, version 3.5 (CCSM3.5) (Wang et al. 2013, 2014). However, GEFA's accuracy is limited by sampling size error, which can be caused by either short data records or a large number of forcings in the forcing matrix. Relatively long time series are typically needed for the traditional GEFA approach to yield stable response patterns, such that the response patterns do not significantly change with varying lengths of data records (Wang et al. 2014). The purpose of this paper is to develop and validate a stepwise GEFA approach using one of the CMIP5 Earth system models, namely the National Center for Atmospheric Research (NCAR) Community Earth System Model (CESM), to reduce the sensitivity of traditional GEFA to sampling size error, thereby yielding more stable atmospheric response fields. The paper is arranged as follows. The statistical method and model experiments are introduced in section 2. In section 3, the dominant oceanic drivers of NTA climate are identified in CESM based on stepwise GEFA. A comparison between the traditional GEFA and advanced stepwise GEFA methods is described in section 4. The advanced stepwise GEFA method is rigorously validated in section 5 using four metrics. Conclusions and discussion are presented in section 6.

\section{Statistical method and model experiments}

\section{a. The traditional GEFA method: Full GEFA}

The traditional GEFA method, herein also called the full GEFA or FGEFA method, is based on the stochastic climate theory proposed by Hasselmann (1976) and Frankignoul and Hasselmann (1977). According to this theory, the coupled climate system, based on time scale, can be divided into a rapidly varying "weather" system (e.g., atmosphere) and a slowly responding "climate" system (e.g., SST and vegetation greenness index). The atmospheric variable $\mathbf{A}$ at time $t \mathbf{A}(t)$ can be decomposed into two terms: one represents the feedback response to the slow-process forcings $\mathbf{O}(t)$, and the other represents atmospheric internal variability $\mathbf{N}(t)$ such that

$$
\mathbf{A}(t)=\mathbf{B O}(t)+\mathbf{N}(t),
$$

where $\mathbf{B}$ is the feedback matrix. While Eq. (1) appears similar to multiple linear regression, $\mathbf{N}(t)$ represents the atmospheric internal variability and has real physical meaning. The term $\mathbf{N}(t)$ can be rather large compared to the error term in multiple linear regression, which is minimized. By multiplying $\mathbf{O}(t-\tau)^{\mathrm{T}}$, where $\tau$ is the time lag, which should be longer than the atmospheric persistence time, and superscript $\mathrm{T}$ indicates a transpose, and applying covariance to both sides of Eq. (1), it is determined that

$$
\begin{aligned}
\left\langle\mathbf{A}(t), \mathbf{O}(t-\tau)^{\mathrm{T}}\right\rangle= & \mathbf{B}\left\langle\mathbf{O}(t), \mathbf{O}(t-\tau)^{\mathrm{T}}\right\rangle \\
& +\left\langle\mathbf{N}(t), \mathbf{O}(t-\tau)^{\mathrm{T}}\right\rangle,
\end{aligned}
$$

where $\langle a, b\rangle$ represents the covariance between $a$ and $b$. Since SST variability at an earlier time $\mathbf{O}(t-\tau)$ cannot force subsequent atmospheric internal variability $\mathbf{N}(t)$ as long as $\tau$ exceeds the memory of the atmosphere ( $\sim 1$ week), the following approximation holds true:

$$
\left\langle\mathbf{N}(t), \mathbf{O}(t-\tau)^{\mathrm{T}}\right\rangle=0 .
$$

Then, the feedback B can therefore be solved as

$$
\mathbf{B}=\frac{\left\langle\mathbf{A}(t), \mathbf{O}(t-\tau)^{\mathrm{T}}\right\rangle}{\left\langle\mathbf{O}(t), \mathbf{O}(t-\tau)^{\mathrm{T}}\right\rangle} .
$$

When $\mathbf{O}$ is a vector containing a single forcing, then $B$ is the feedback coefficient, and this equation represents the univariate equilibrium feedback assessment (Liu et al. 2006; Notaro et al. 2006). When $\mathbf{O}$ is a matrix containing multiple forcings, then $\mathbf{B}$ is the feedback matrix, and this equation represents GEFA (Liu et al. 2008; Wen et al. 2010). The GEFA method has been applied to examine the impacts of North Pacific SST variability in NCAR CCSM3 (Zhong and Liu 2008), global SST variability on observed patterns of geopotential height (Wen et al. 2010), U.S. precipitation (Zhong et al. 2011), and oceanic and vegetation variability on North American temperature and precipitation in observations and CCSM3.5 (Wang et al. 2013, 2014). The reliability of GEFA in terms of quantifying the forcing of either SSTs or leaf area index (LAI) on the atmosphere has been explored by several studies using a conceptual model (Liu et al. 2012a,b) and fully coupled CCSM3.5 (Wang et al. 2013, 2014). 
The accuracy of GEFA is limited by sampling errors, mostly in the cross-covariance matrix of SST variability $\left\langle\mathbf{O}(t), \mathbf{O}(t-\tau)^{\mathrm{T}}\right\rangle$ (Liu et al. 2008). Previous studies reduced this error by setting $\tau$ to 1 month (Wen et al. 2010) and using truncated SST empirical orthogonal function (EOF) space as forcing fields, which can significantly decrease the singularity of the covariance matrix of SST variability (Liu et al. 2008; Wen et al. 2010; Zhong et al. 2011; Wang et al. 2013, 2014).

The statistical significance of GEFA is assessed using the Monte Carlo bootstrap method (Czaja and Frankignoul 2002). First, for each grid cell, the time series of the atmospheric field is randomly scrambled by year, and a new GEFA coefficient GEFAm is computed using this scrambled atmospheric time series. Next, the first step is repeated 500 times, and 500 GEFAm values are obtained. The first and second steps are then repeated for each grid cell. Finally, the significance of the atmospheric response field is determined at each grid cell by the percentage of GEFA coefficients from the scramble time series that are smaller in absolute magnitude than the GEFA coefficients from the original time series. In this paper, $95 \%$ is chosen as the confidence level for statistically significant responses.

The advantages of GEFA are multifold. First, to study atmospheric responses to oceanic forcings in the real world, only a statistical method can be applied given that observations represent only one realization. Second, although GEFA is a statistical method, it can offer real physical meaning, unlike other statistical methods such as multiple linear regression. Third, compared to other statistical methods, such as partial correlation, composite analysis, residual EFA, and lagged maximum covariance analysis, GEFA can quantify the contributions of each forcing in a unified framework without prior knowledge of the relationship among forcings. Fourth, the accuracy of GEFA can be demonstrated using fully coupled climate models. Finally, the statistical method is easily applied, with no need for computationally expensive modeling experiments. Studies by Wen et al. (2010) and Frankignoul et al. (2011) provide detailed comparisons of GEFA with EFA, residual EFA, and lagged maximum covariance analysis.

Although using truncated SST EOF spaces as forcing fields can decrease sampling errors by suppressing the singularity of the SST covariance matrix $\left\langle\mathbf{O}(t), \mathbf{O}(t-\tau)^{\mathrm{T}}\right\rangle$ (Liu et al. 2008), the traditional GEFA approach can still yield substantial sampling errors when the analyzed time series is short in duration or the number of forcings is large. The traditional GEFA method, which applies the full forcing matrix, is conventionally denoted by full GEFA, to distinguish from the improved stepwise GEFA approach, which only applies a subset of the full forcing matrix.

\section{b. Development of the advanced stepwise GEFA approach}

In this study, we advance the traditional GEFA method by dropping the relatively unimportant forcings from the full forcing matrix to minimize the sampling errors. Using a backward-selection stepwise method (Hocking 1976), which has been utilized to develop prediction models (Yin et al. 2014; Segele et al. 2015; Yu et al. 2015), a statistical prediction model is built, and the most important forcings as predictors of the atmospheric variable are selected through an automated procedure. Then, the relative quality of a statistical model is measured by the Akaike information criteria (AIC; Akaike 1974) through estimating the goodness of fit and penalizing the complexity of the model:

$$
\mathrm{AIC}=2 N_{f}-2 \ln (\hat{L}),
$$

where $N_{f}$ represents the number of forcings in the forcing matrix, and $\hat{L}$ stands for the maximized likelihood function of the model, which is estimated as follows:

$$
\begin{gathered}
\hat{L}=-\frac{L}{2} \ln \left\{\sum_{t=1}^{L}[\hat{\mathbf{A}}(t)-\mathbf{A}(t)]^{2} / L\right\}+C_{1} \text { and } \\
\hat{\mathbf{A}}(t)=\mathbf{B O}(t),
\end{gathered}
$$

where $L$ is the data record length, $C_{1}$ is a constant independent of $\mathbf{B}$, and $\hat{\mathbf{A}}(t)$ is estimated atmospheric condition at time $t$. The details are as following. In step 1 , for each grid cell, GEFA is applied with 17 SST forcings as in Eq. (5), and the AIC $\left(\mathrm{AIC}_{17}\right)$ is calculated using Eq. (6). In step 2, one forcing is dropped from the full forcing matrix [Eq. (5)] at a time, and then the AIC associated with this 16 -forcings model is calculated as in Eq. (6). In step 3, the 16-forcings model with the lowest AIC value is selected, and its $\mathrm{AIC}\left(\mathrm{AIC}_{16}\right)$ is compared with the 17 -forcings model $\left(\mathrm{AIC}_{17}\right)$. If $\mathrm{AIC}_{16}$ is less than $\mathrm{AIC}_{17}$, then the 16-forcings model is preferred. The steps are then repeated, eliminating one forcing at a time until no further reduction is justified. For each grid cell, the impacts of those dropped forcings are set to 0 . By reducing the number of forcings considered simultaneously by GEFA, the sampling error is significantly reduced and the reliability of estimated feedbacks associated with the remaining forcings is enhanced. On average, roughly half of the forcings can be eliminated from the forcing matrix through stepwise selection.

Besides the advantages of full GEFA mentioned above, stepwise GEFA (herein called SGEFA) has another advantage, which is especially useful when two forcings in the forcing matrix are highly correlated with each other. The higher the correlation of the two 
forcings with each other, the more singular is the SST covariance matrix $\left\langle\mathbf{O}(t), \mathbf{O}(t-\tau)^{\mathrm{T}}\right\rangle$, and the larger the sampling error of $\mathbf{B}$ estimates. In this situation, stepwise GEFA only keeps the relatively important forcings to avoid singularity.

\section{c. SST forcings considered in this study}

In this paper, to determine which ocean basin SST is most important to NTA climate, the global ocean is divided into eight nonoverlapping basins (see Fig. S1 in the supplemental material): the tropical Pacific (TP; $\left.20^{\circ} \mathrm{S}-20^{\circ} \mathrm{N}, 120^{\circ} \mathrm{E}-60^{\circ} \mathrm{W}\right)$, North Pacific (NP; $20^{\circ}-60^{\circ} \mathrm{N}$, $120^{\circ} \mathrm{E}-100^{\circ} \mathrm{W}$ ), South Pacific (SP; $60^{\circ}-20^{\circ} \mathrm{S}, 150^{\circ} \mathrm{E}-$ $70^{\circ} \mathrm{W}$ ), tropical Indian Ocean (TI; $20^{\circ} \mathrm{S}-20^{\circ} \mathrm{N}, 35^{\circ}-$ $105^{\circ} \mathrm{E}$ ), south Indian Ocean (SI; $60^{\circ}-20^{\circ} \mathrm{S}, 20^{\circ}-120^{\circ} \mathrm{E}$ ), tropical Atlantic (TA; $\left.20^{\circ} \mathrm{S}-20^{\circ} \mathrm{N}, 70^{\circ} \mathrm{W}-20^{\circ} \mathrm{E}\right)$, North Atlantic (NA; $\left.20^{\circ}-60^{\circ} \mathrm{N}, 90^{\circ}-10^{\circ} \mathrm{W}\right)$, and South Atlantic (SA; $60^{\circ}-20^{\circ} \mathrm{S}, 70^{\circ} \mathrm{W}-20^{\circ} \mathrm{E}$ ). The principal component (PC) time series corresponding to the leading two EOF modes for SSTs in each ocean basin are then combined into a single forcing matrix. The seasonal cycle and the third-order polynomial trend are removed from the SST data. Results do not change if the forcing matrix is expanded to include the leading three to five EOF modes for each ocean basin. Also, the results are largely insensitive of the exact geographical extent of the select boxes. According to previous studies, Mediterranean SST anomalies also potentially affect North African climate (Rowell 2003; Jung et al. 2006; Gaetani et al. 2010), so the area-averaged Mediterranean SSTs (MED) are also included as a forcing. Therefore, the full forcing matrix used in this study consists of

$$
\begin{aligned}
\mathbf{O}= & {[\mathrm{TP} 1, \mathrm{TP} 2, \mathrm{NP} 1, \mathrm{NP} 2, \mathrm{TA} 1, \mathrm{TA} 2, \mathrm{NA} 1, \mathrm{NA} 2,} \\
& \text { TI1, TI2, SP1, SP2, SA1, SA2, SI1, SI2, MED]. }
\end{aligned}
$$

For example, TP1 and SI2 represent the first PC of tropical Pacific SST and the second PC of south Indian Ocean SST, respectively. The spatial patterns and time series of SST anomalies associated with TP1, TI1, and TA1 for January (representing DJF), April (representing MAM), July (representing JJA), and October (representing SON) are shown in Fig. 2 and Fig. S3 in the supplemental material. The spatial patterns for all 16 oceanic modes for January, April, July, and October are shown in Figs. S1 and S2 in the supplemental material.

\section{d. NCAR CESM}

In this study, the fully coupled global climate model, CESM version 1.2 (Hurrell et al. 2013), is used to validate the statistical GEFA method. The active components applied in this study include the Community
Atmosphere Model, version 5.3 (CAM5.3; Neale et al. 2010); Community Land Model, version 4.0, with Carbon-Nitrogen Dynamic Global Vegetation Model (CLM4-CNDV; Oleson et al. 2010; Lawrence et al. 2011); Parallel Ocean Program, version 2 (POP2; Smith et al. 2010); and Community Ice Code, version 4 (CICE4; Hunke et al. 2008). A 2050-yr offline CLM4CNDV run is first performed to allow the terrestrial carbon and nitrogen pools to reach equilibrium, and then the fully coupled control simulation of CESM is spun up for another $100 \mathrm{yr}$. At that time, the absolute value of globally averaged monthly mean net ecosystem exchanges oscillated around $\pm 0.05 \mathrm{PgC} \mathrm{yr}^{-1}$ (Hoffman et al. 2008), with no significant trend in any of the key Earth system variables (e.g., SST, LAI, soil moisture, and fractional cover of plant functional types). The run is extended another $300 \mathrm{yr}$ to serve as the control simulation (CTL) and is used to statistically assess the atmospheric responses across NTA to individual oceanic forcings. The seasonal cycle and third-order polynomial trend are removed from output of the 300-yr CTL run.

\section{e. Dynamical experiments}

The atmospheric responses to a specific oceanic forcing can also be obtained in a climate model through ensemble sensitivity experiments. Two-month-long, data-ocean/data-ice dynamical experiments are designed for each calendar month and specific oceanic forcing, with each run starting from the previous month's restart file from the CTL run. The prescribed sea ice field is the climatological sea ice fraction from the CTL run. The prescribed SST field is a positive or a negative SST EOF anomaly pattern over the focal ocean basin imposed onto global climatological SSTs from the CTL run. For each calendar month and specific forcing, ensembles with 20 positive $P$ and 20 negative $N$ members are produced, with each member starting from a different year. Atmospheric responses in $P$ and $N$ are compared with the climatology $C$ from the CTL run. Here $P-C$ and $C-N$ are considered as the atmospheric response of each ensemble member to the specific oceanic forcing. Statistical significance of the atmospheric responses in the dynamical experiments is determined based on the Student's $t$ test, based on the $95 \%$ confidence level. Here, the atmospheric responses to an oceanic forcing are analyzed in the second month of the experiment, since the atmosphere needs some time to reach equilibrium. Forty ensemble members are determined to be sufficient by examining the ensemble-mean atmospheric response to specific oceanic forcing with increasing number of ensemble members (not shown). As shown later in section 3, the first EOF modes of tropical Pacific SST (TP1), tropical Indian Ocean SST (TI1), and tropical 
TP1
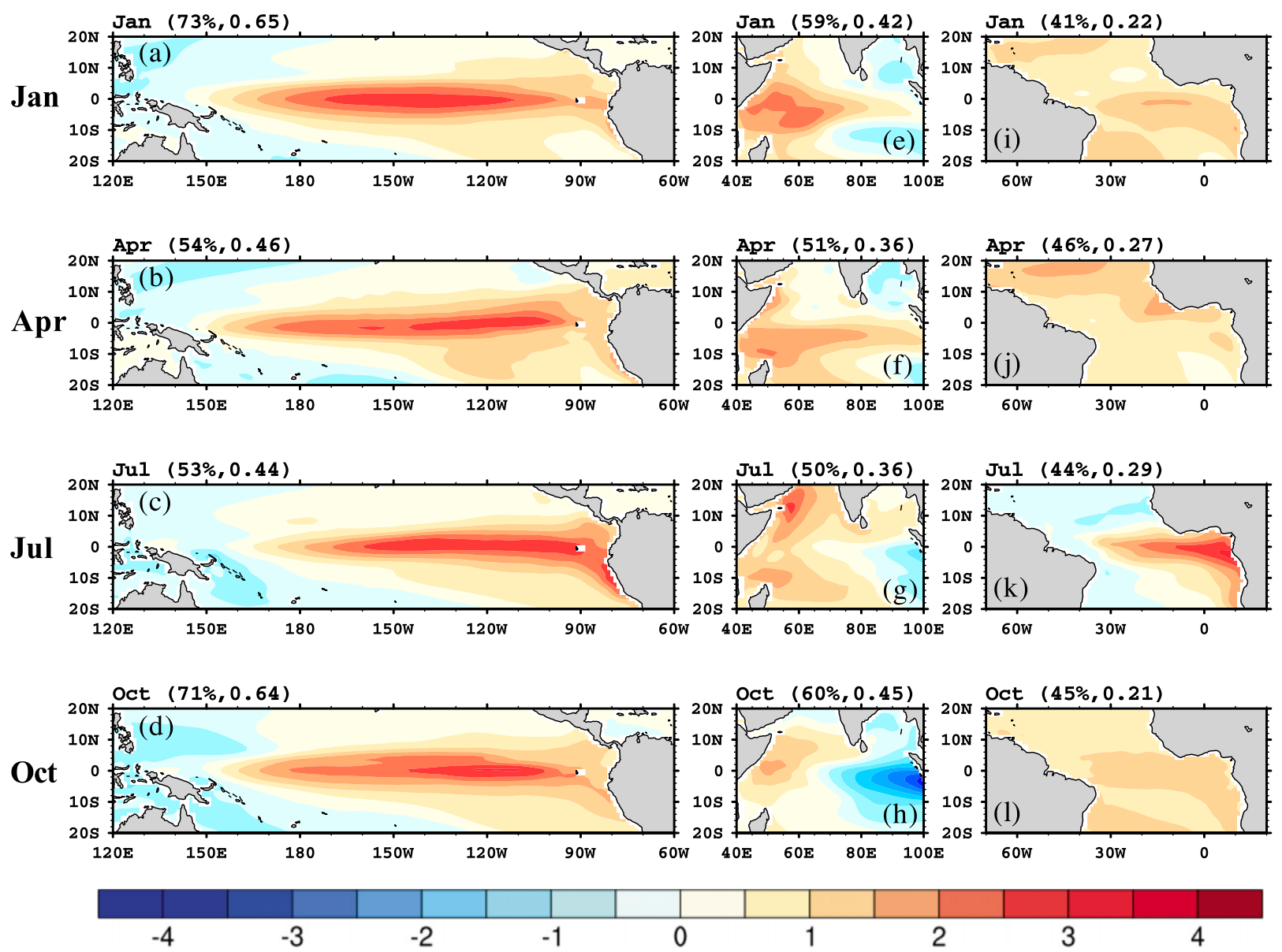

$-4$

$-3$
$-1$
TI1

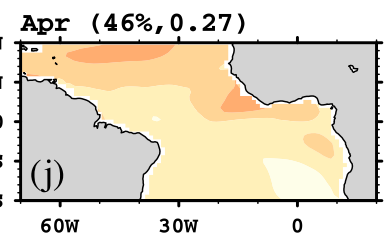

FIG. 2. Spatial pattern of SST anomalies associated with the first EOF mode (unitless) of (a)-(d) TP1, (e)-(h) TI1, and (i)-(1) TA1 for January, April, July, and October in the CTL run. The explained variance $(\%)$ and standard deviation $\left({ }^{\circ} \mathrm{C}\right)$ of the corresponding principal components are indicated in parentheses.

Atlantic SST (TA1) are the three most important oceanic drivers of NTA climate in CESM. For TP1 and TI1, onestandard-deviation anomalies in SST are added, and for TA1, because of its weak forcing, two-standard-deviation anomalies are added in order to improve the signal-to-noise ratio. The dynamical assessments are completely independent of the statistical assessments, thereby providing an independent check of the statistical GEFA approach.

\section{f. CESM Large Ensemble Community Project data}

As with other statistical methods, the accuracy of GEFA is affected by data sampling size, namely the length of the data record. Output from the CESM Large Ensemble Community Project (CESM-LENS; Kay et al. 2015), which has 40 ensemble members under historical forcing from 1920 to 2005, can be merged into a single 3440-yr data record by connecting monthly anomaly outputs of all ensemble members ( 40 ensemble members $\times 86 \mathrm{yr})$. The seasonal cycle and third-order polynomial trend are removed from raw output for each ensemble member. Each model realization differs from one another by only small round-off level variations in their atmospheric initial conditions. All simulations apply CESM, version 1.0 (CESM1; Hurrell et al. 2013), with CAM5 (Neale et al. 2010) as its atmospheric component. The model resolution is roughly $1^{\circ}(\mathrm{gx} 1 \mathrm{v} 6$; $0.9^{\circ} \times 1.25^{\circ}$ latitude-longitude). The CESM-LENS, whose configuration is similar with the model used in this study, provides a test bed to estimate the minimum data record length required for obtaining stable GEFA response estimates to oceanic forcings.

\section{Important oceanic drivers of NTA climate in CESM based on stepwise GEFA}

The relative importance of each oceanic mode to NTA climate in CESM is measured by the percentage of 
area with significant $(>95 \%$ confidence level) atmospheric responses in 2-m air temperature and precipitation, per oceanic forcing and calendar month (Figs. 3a,e). It is clearly shown that tropical oceanic forcings (Fig. 3) are dominant drivers of NTA climate in CESM, which is consistent with other studies using different climate models (Folland et al. 1986; Giannini et al. 2003; Lu and Delworth 2005; Hoerling et al. 2006). Results for three study regions, namely the Sahel (Figs. 3b,f), GC (Figs. 3c,g), and GHA (Figs. 3d,h), are also shown, since the dominant drivers of each region's climate are not the same. The study regions defined here are broader than the observed established extent. TP1, which represents ENSO, substantially impacts air temperature and precipitation for all three African subregions in nearly all months. TI1, which in CESM consists of the Indian Ocean Basin (IOB) mode during February-July and the Indian Ocean dipole (IOD) mode during August-January, affects temperature and precipitation across the GHA in almost all seasons, especially the "short rains" (OND). TA1, which represents the Atlantic Niño mode during June-August in CESM, regulates air temperature and precipitation over the GC region and Sahel during the pre- and peakmonsoon season. TP2, which is characterized by the tropical Pacific meridional mode during October-May in CESM, affects temperature and precipitation over the GHA. TI2, which is similar to the IOB during AugustJanuary in the model, influences GHA temperature and precipitation. Compared with the tropical oceanic forcings, the impact of extratropical oceanic forcings on NTA climate is seemingly minor (Fig. 3).

In summary, of the 17 SST modes, five are distinctly important to NTA climate in CESM. These dominant modes include TP1 and TA1 for the Sahel and GC region and TP1, TI1, TI2, and TP2 for the GHA. However, the magnitudes of the impacts of TP2 and TI2 on northern and tropical African climate are small (figures not shown). Therefore, in the following sections, the top three key oceanic modes for regulating NTA climate in CESM, namely, TP1, TI1, and TA1, are chosen for comparison between full and stepwise GEFA and for validating stepwise GEFA compared to dynamic experiments.

\section{Comparison of full GEFA and stepwise GEFA}

As discussed in section 2, sample size, or more specifically, the length of data record, is a critical factor that limits GEFA's accuracy. Knowing the minimum length of data record needed for stable GEFA results is crucial, particularly for observational studies given the relatively short duration of most observational records. It also provides guidance for the necessary length of the CTL run. In this section, the minimum required data record is assessed for, and compared between, full and stepwise GEFA in order to examine the expected advantages of stepwise GEFA. To perform a comprehensive evaluation of the length of data required for stable GEFA responses, a diverse set of variables is considered, including local latent (LHFLX) and sensible (SHFLX) heat fluxes over the corresponding forcing ocean basin; 850-hPa (Z850) and 200-hPa (Z200) geopotential heights and $500-\mathrm{hPa}$ vertical velocity $(\omega 500)$ over the tropics and subtropics $\left(35^{\circ} \mathrm{S}-35^{\circ} \mathrm{N}\right.$, all longitudes); and 2-m air temperature (Temp) and precipitation (Precip) over northern and tropical Africa $\left(10^{\circ} \mathrm{S}-17^{\circ} \mathrm{N}\right.$, $\left.20^{\circ} \mathrm{W}-55^{\circ} \mathrm{E}\right)$.

The GEFA results are considered stable when the estimated response patterns do not change significantly with a further increase in sample size. Instead of performing an extremely long CTL run, CESM-LENS provides an ideal testing ground. By connecting all 40 ensemble members, a 3440-yr data record is constructed. The spatial correlation between GEFA responses using a subset of the data $\left(\mathrm{GEFA}_{\text {short }}\right)$ and its full record $\left(\mathrm{GEFA}_{\text {long }}\right)$ is calculated. The length of the shorter subset data records is allowed to vary from 20 to $300 \mathrm{yr}$ in increments of $20 \mathrm{yr}$ and from 300 to $600 \mathrm{yr}$ in increments of $50 \mathrm{yr}$. For analysis of shorter time periods, the full 3440-yr data record is divided into several segments. For example, when considering 50-yr time periods, the 3440 -yr data record is divided into 68 segments, and spatial correlations are then calculated between the response field from GEFA long $_{\text {and that from each GEFA }}$ short segment. The medium value among those spatial correlations is defined as the spatial correlation between GEFA $_{\text {long }}$ and GEFA $A_{\text {short }}$ for a specific data length. The GEFA-based response estimate is considered stable, or reliable, when this medium spatial correlation exceeds a specified value. To avoid subjectivity, a series of correlation coefficients, ranging from 0.7 to 0.95 in increments of 0.01 , are applied to check the required minimum length of data record. The length of data record needed by full GEFA and stepwise GEFA is evaluated separately. The length of minimum data record needed by full GEFA is determined based on the spatial correlation between response fields from $\mathrm{GEFA}_{\text {long }}$ and $\mathrm{GEFA}_{\text {short }}$ using full GEFA. Likewise, the length needed by stepwise GEFA is found based on spatial correlation between response fields from GEFA $A_{\text {long }}$ and GEFA $_{\text {short }}$ using stepwise GEFA. These can be compared because the spatial correlation between response fields from GEFA $_{\text {long }}$ using full GEFA and stepwise GEFA is very high, with a mean correlation across seven variables (SHFLX, LHFLX, Z850, Z200, w500, Temp, and Precip) and 12 months of 0.96 . 

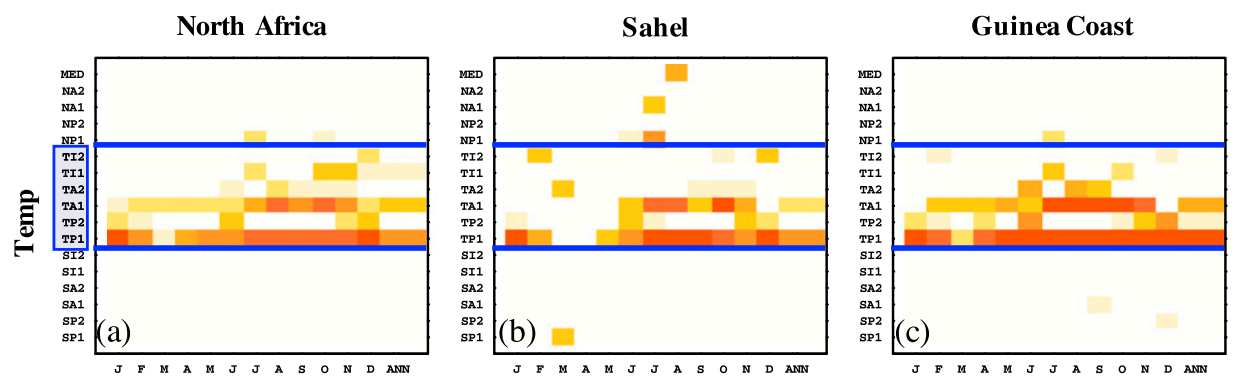

Greater Horn of Africa
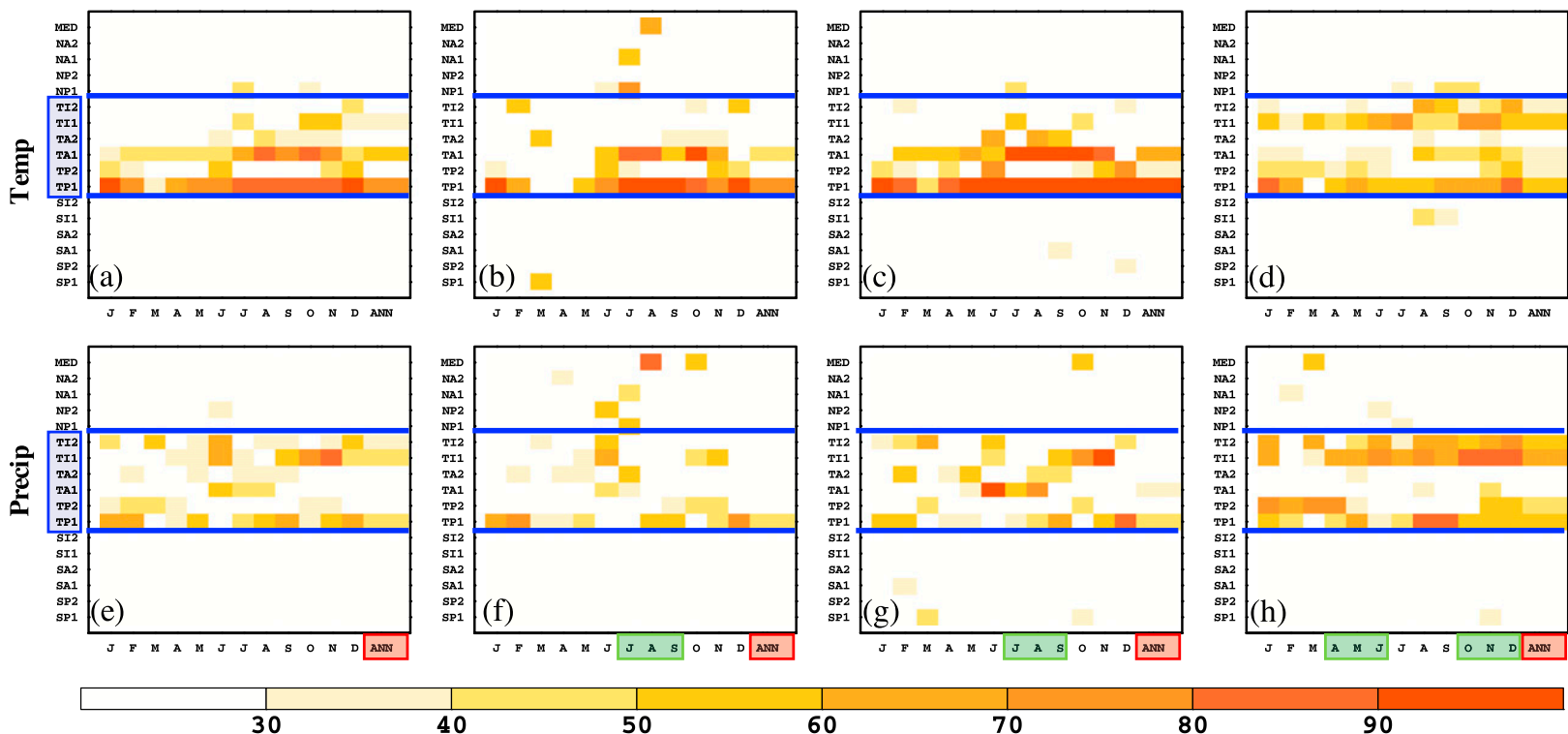

40

50

60

$70 \quad 80$

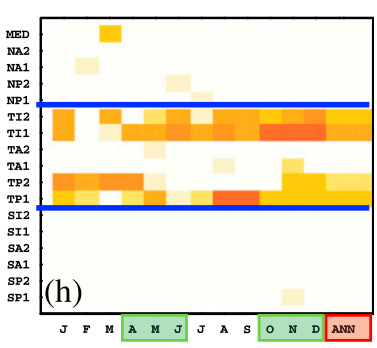

FIG. 3. Percentage of area with significant responses $(95 \%+$ confidence level, based on the Monte Carlo bootstrapping method) in (a)-(d) Temp or (e)-(h) Precip by month across the Sahel, the Guinea Coast, the Greater Horn of Africa, or entire area of northern and tropical Africa $\left(10^{\circ} \mathrm{S}-20^{\circ} \mathrm{N}, 20^{\circ} \mathrm{W}-50^{\circ} \mathrm{E}\right)$ to 17 individual oceanic modes, based on the application of stepwise GEFA to the CTL run. The annual mean percentage of area with significant responses is shown as the last column of each panel figure (red boxes). The tropical oceanic modes are indicated within the blue lines. The green boxes denote the wet seasons per region.

To give a general overview of the minimum sample size needed for stable GEFA response estimates to each forcing at different spatial correlations (0.7-0.95), the length of data record required by full GEFA and stepwise GEFA is averaged across the aforementioned seven variables and 12 months (Fig. 4). Both GEFA methods show a positive monotonic relationship between the minimum required data record and the spatial correlation, such that the higher the spatial correlation, the longer the required data record. Using the same length of data record, stepwise GEFA has a better spatial pattern reproduction of the full 3440-yr results than full GEFA. For instance, using a 50-yr data record, full GEFA fails to capture the spatial pattern of atmospheric responses to TP1 (TI1 and TA1 are similar) whereas stepwise GEFA exhibits a spatial correlation of 0.7 (Fig. 4a). Likewise, for a given target spatial correlation, stepwise GEFA can yield much more stable results with shorter data records than full GEFA. For example, when targeting a spatial correlation of 0.75 , stepwise GEFA requires a minimum 56-yr data record, whereas full GEFA requires a minimum 93-yr data record to capture stable atmospheric responses to TI1 (Fig. 4b; TP1 and TA1 are similar). The difference in response fields between full GEFA and stepwise GEFA diminishes with increasing length of the data record, and finally their response fields are nearly identical when the complete $3440-y r$ data record is analyzed. It is noteworthy that this monotonic relationship is not linear; as the length of the data record increases, the rate of increasing spatial correlation decelerates. For example, the spatial correlation increases at rates of $+0.30[=(0.85-0.7) / 50 \mathrm{yr} \times 100 \mathrm{yr}$ century $\left.^{-1}\right],+0.08$, and +0.04 century $^{-1}$ as the analyzed data record increases from 51 to $100 \mathrm{yr}$, from 101 to $150 \mathrm{yr}$, and from 151 to $300 \mathrm{yr}$, respectively, to TP1 forcing.

In summary, stepwise GEFA does not require as long of a time series as full GEFA in order to achieve stable GEFA response estimates. Therefore, a shorter CTL run may suffice to accurately estimate GEFA responses, and in the case of analyzing short observational records, a more reliable response can be obtained. Furthermore, stepwise GEFA can achieve a more accurate decomposition of responses when highly correlated forcings exist in the forcing matrix. The advantage of stepwise GEFA in obtaining reliable response field is more obvious when the time series is short. The necessary minimum length of data record needed grows exponentially with increasing target threshold in spatial correlation.

\section{Validation of the statistical stepwise GEFA method}

To validate the statistical stepwise GEFA method, the atmospheric responses to a specific oceanic forcing are 
TP1

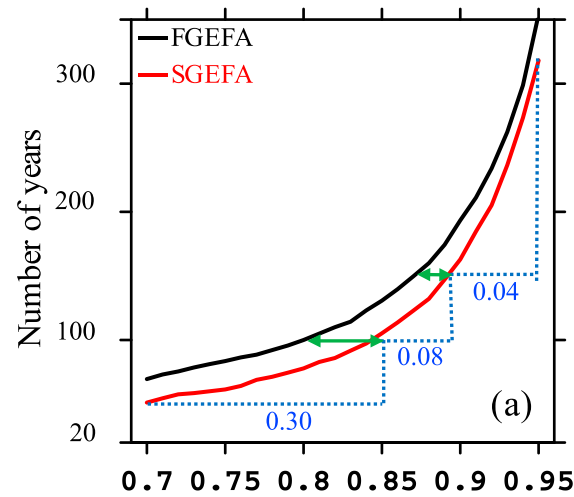

TI1

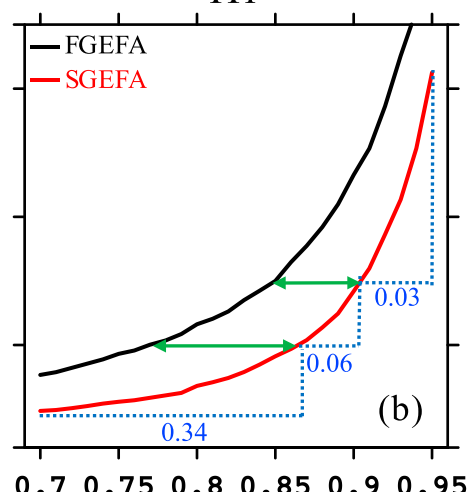

Spatial correlation

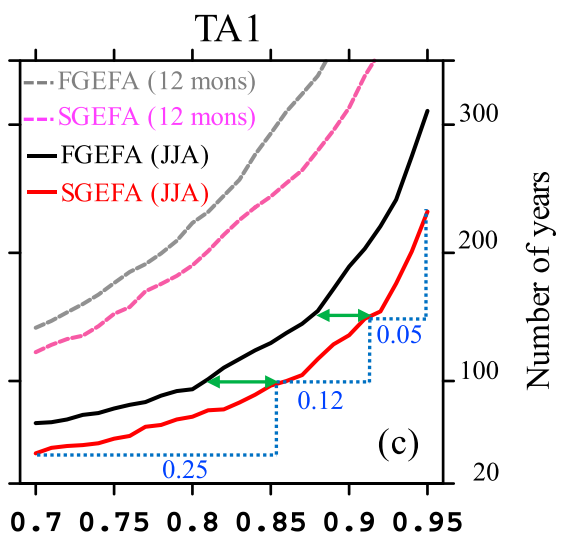

$\begin{array}{llllllll}0.7 & 0.75 & 0.8 & 0.85 & 0.9 & 0.95\end{array}$

FIG. 4. Length of data record required for stable estimates of GEFA response fields averaged across seven variables and 12 months to tropical oceanic forcings from (a) TP1, (b) TI1, and (c) TA1 by FGEFA (black lines) and SGEFA (red lines) with increasing spatial correlation in CESM-LENS. The spatial correlation in the $x$ axis is the medium value of spatial correlations between the response field of

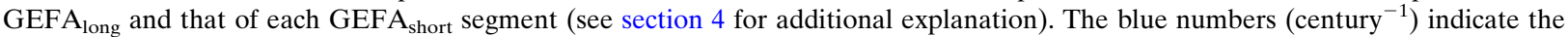
growth rate of the spatial correlation with increasing data record length. For TA1, results are shown both for the full annual cycle of 12 calendar months [FGEFA (gray) and SGEFA (pink)] and only JJA [FGEFA (black) and SGEFA (red)] on account of weak forcing and no clear physical meanings of TA1 during September-May.

estimated independently through CESM dynamic experiments and compared to the stepwise GEFA-based statistical assessment, as applied to the CTL run. It is noted that several factors complicate the comparison between the statistical and dynamical assessments. First of all, inconsistencies may emerge if the relationship between an oceanic forcing and its atmospheric response is not purely linear. For example, the statistical assessments estimate the feedback using the forcing strength that covers the full spectrum in the CTL run, while the dynamical assessments estimate the feedback according to fixed forcing strengths of one- or twostandard-deviation anomalies. Second, dynamic experiments yield atmospheric responses to specific imposed forcings, even if the forcings do not independently exist in the CTL run. However, stepwise GEFA compares the importance of each oceanic forcing first, and then drops all unimportant forcings. In this situation, the forcing whose existence is totally dependent on other forcings will be eliminated from the statistical assessment, leading to potential inconsistencies between the two assessments. Finally, both assessments have sampling errors given limited ensemble members and sample size. In this section, the validation of stepwise GEFA compared to the dynamic experiments is rigorously performed based on four metrics, namely consistency, spatial correlation, response magnitude, and consistency in mechanisms.

\section{a. Metric 1: Consistency}

The consistency of atmospheric response patterns between statistical stepwise GEFA and dynamic experiments is checked for each important oceanic forcing (TP1, TI1, and TA1) to NTA climate and for each calendar month (Figs. 5a-c). The relationship between statistical and dynamical assessments for each grid cell is classified into five categories: 1) the atmospheric responses in both assessments are significant $(95 \%+)$ and of the same sign (blue bars in Figs. 5a-c);2) neither response is significant (green bars); 3) the dynamical response is significant, while the statistical response is insignificant (orange bars); 4) the dynamical response is insignificant, while the statistical response is significant (pink bars); or 5) both responses are significant but of opposite sign (red bars). Categories 1 and 2 indicate a consistent agreement between statistical and dynamical assessments, categories 3 and 4 represent inconsistency in terms of significance, and category 5 indicates complete inconsistency. In general, the statistical and dynamical assessments yield fairly good agreement in terms of the atmospheric responses to tropical oceanic forcings in CESM, despite the aforementioned factors that complicate the comparison. The percentage of totally inconsistency is extremely low, generally less than $5 \%$, across the 12 months (red bars in Figs. $5 \mathrm{a}-\mathrm{c}$ ). The percentage of consistent agreement, represented by a combination of categories 1 and 2, is $69 \%$ for TP1, $61 \%$ for TI 1 , and $62 \%$ for TA 1 .

When the percentage of consistency is relatively low, as seen with the atmospheric responses to TP1 forcing in March, TI1 forcing in February and March, and TA1 forcing in September-May, the inconsistency is largely associated with category 3 , in which dynamical response 


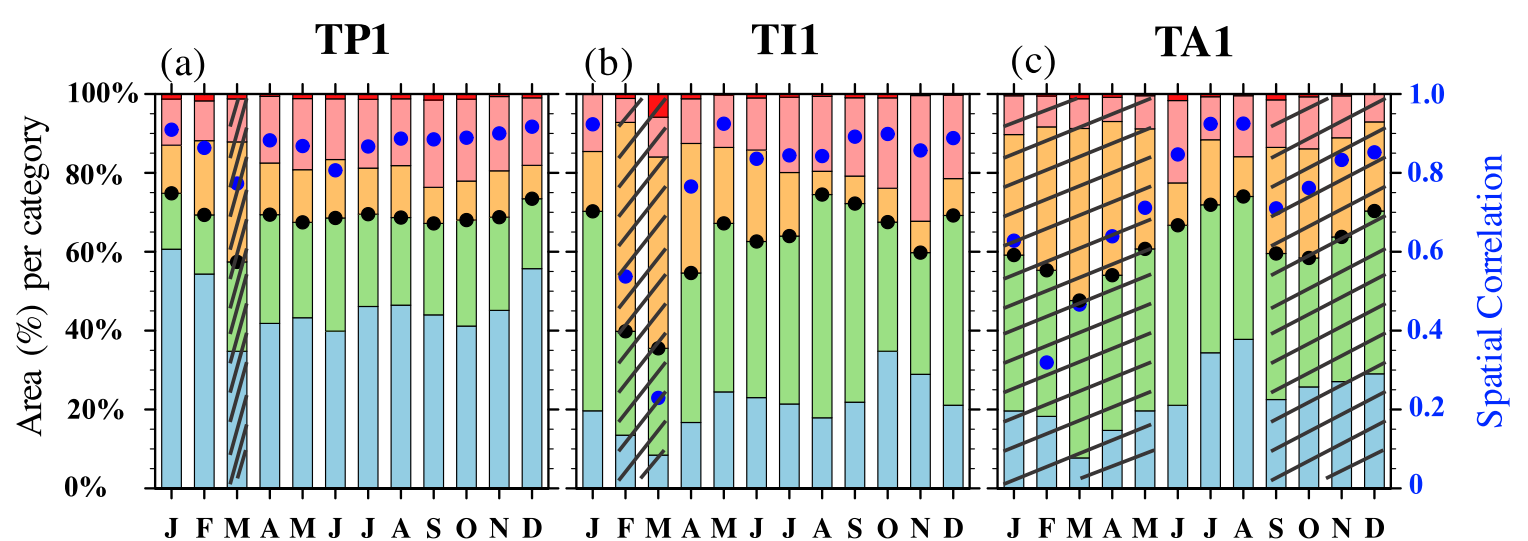
1 Both $S$ and $D$ are significant and have the same sign
2 Both $S$ and $D$ are insignificant
$4 \quad D$ is insignificant, $S$ is significant
3 D is significant, $S$ is insignificant
5 Both $S$ and $D$ are significant but have opposite signs

- Percentage of consistency

Spatial correlation between $\mathrm{S}$ and $\mathrm{D}$

(d)

(e)

(f)

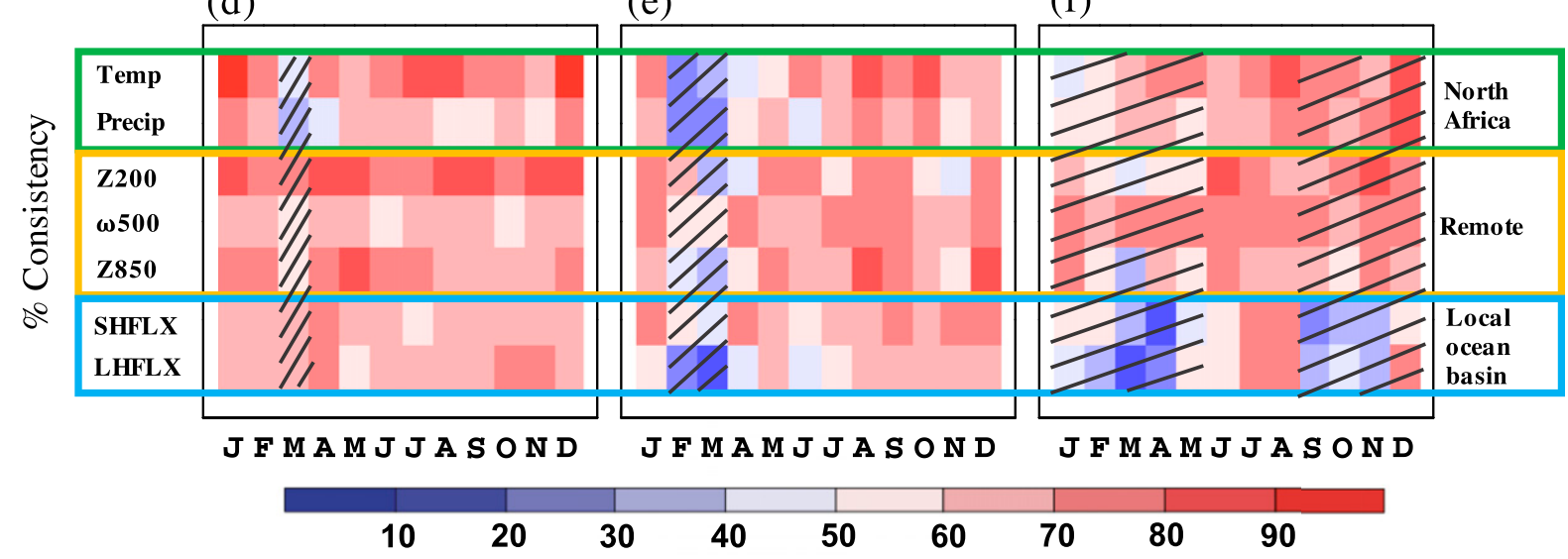

(g)

(h)

(i)
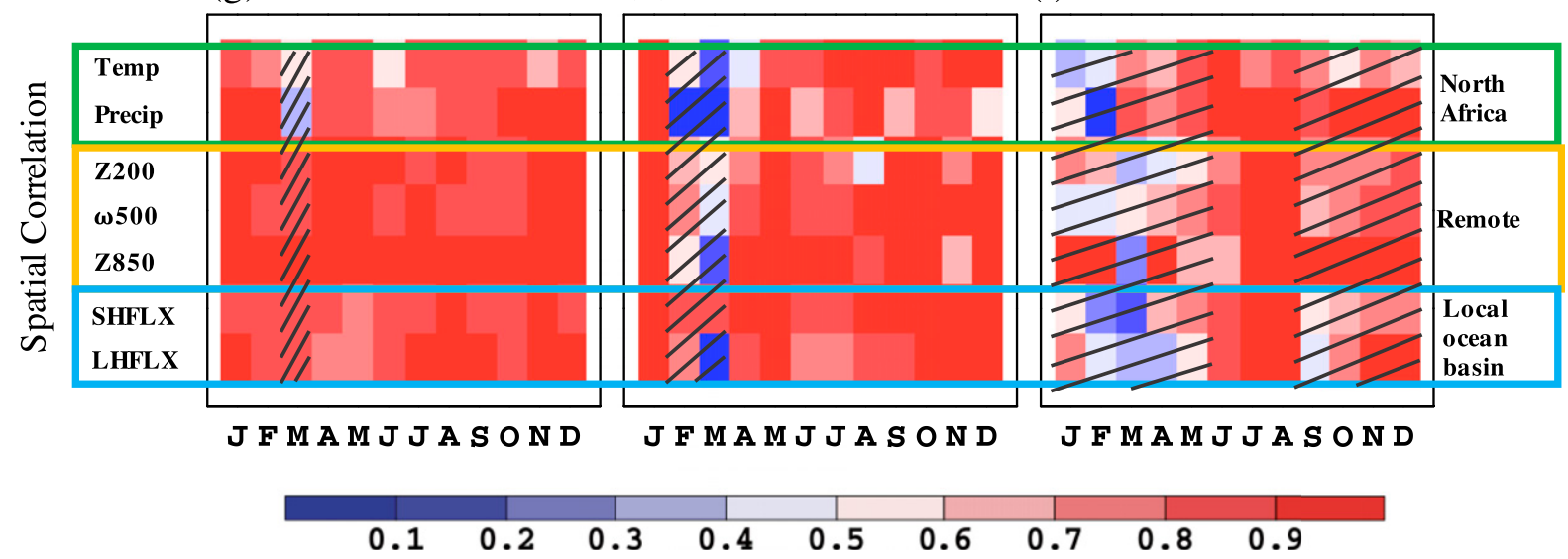

FIG. 5. Statistical SGEFA (S) and dynamical (D) assessment comparison in CESM. Percentage of area covered by each category for (a) TP1, (b) TI1, and (c) TA1 is averaged across seven variables. Black dots indicate percentage of consistency by month, and blue dots represent the spatial correlation between the statistical and dynamical assessments averaged by month. Also shown are the percentage of area with consistent response between statistical and dynamical assessment in CESM for (d) TP1, (e) TI1, and (f) TA1 forcings, and the spatial correlation of response patterns between statistical and dynamical assessment in CESM for (g) TP1, (h) TI1, and (i) TA1 forcings. Hatching indicates that the inconsistency is caused by a high correlation between TP1 and TI1 ( $\sim 0.88)$ or the weak forcing of TA1. 
is significant but the statistical response is not (orange bars in Figs. 5a-c). Because of a high temporal correlation between TP1 and TI1, the atmospheric responses to TI forcing in nearly all seven variables exhibit low consistency in February and March (Fig. 5e), with the inconsistency again primarily associated with category 3 . The reasons for this low consistency are further explored in the supplemental material. Unlike TI1, the poor agreement between statistically and dynamically assessed atmospheric responses to TA1 forcing is mainly restricted to sensible and latent heat flux during September-May, because of the weak TA1 forcing during these months. With stepwise GEFA, TA1 is usually dropped because of its much lower importance compared to other oceanic forcings, so most stepwise GEFA response fields are insignificant. However, although the TA1 forcing is weak, the dynamic experiments still detect some significant local sensible and latent heat flux responses, leading to low consistency between statistically and dynamically assessed sensible and latent heat fluxes. For other remote variables, since both assessments indicate insignificant responses, better agreement results between the two assessments. Since the atmospheric responses to TI1 during FebruaryMarch are insignificant, and the EOF modes of TA1 during September-May do not have clear physical meanings, the atmospheric responses in these months are omitted (hatched months in Figs. 5-7). In summary, excluding the hatched month results, the percentage of consistent response fields between the statistical and dynamical assessments is $70 \%$ for TP $1,67 \%$ for TI 1 , and $71 \%$ for TA1.

\section{b. Metric 2: Spatial correlation}

The spatial correlation between the statistically and dynamically estimated response fields is calculated for each oceanic forcing using only grid cells that attain statistical significance in both assessments. The mean spatial correlation, averaged across seven response variables and 12 months, is 0.87 for TP1, 0.79 for TI1, and 0.72 for TA1 (averaged over blue dots in Figs. 5a-c). Excluding the hatched month results, which are associated with insignificant atmospheric responses (TP1 in February, TI1 in February-March) and have no clear physical meaning (TI1 during September-May), the average spatial correlation is 0.95 for TP1, 0.87 for TI 1 , and 0.90 for TA1. By decomposing the metric into its seven component variables, it is determined that $94 \%$ of the variables by month are characterized by correlations exceeding 0.7 . In conclusion, statistically and dynamically estimated responses are highly correlated with each other, in further support of the stepwise GEFA's credibility.

\section{c. Metric 3: Response magnitude}

In this part, the seasonal cycle of area-averaged responses in 2-m air temperature (Fig. 6) and precipitation (Fig. 7) across three NTA subregions to TP1, TI1, and TA1 forcings are estimated in CESM using the statistical and dynamical assessments. To quantitatively measure the difference between statistical and dynamical assessments, the root-mean-square error (RMSE) for each forcing and region is calculated using nonhatched area information, with the magnitude of insignificant responses assigned as zero.

In terms of response significance and sign, statistical assessments correspond closely to dynamical assessments, and among all the nonhatched months $(11,10$, and 3 months in TP1, TI1, and TA1, respectively) and regions, $88 \%$ of $2-\mathrm{m}$ air temperature responses are consistent between the two assessments. Both the statistical and dynamical assessments indicate that El Niño (TP1) favors higher air temperature across the three regions (Figs. 6a-c). The impact on air temperature peaks in winter (December-January), with response magnitudes of $0.66^{\circ} \mathrm{C}\left(0.64^{\circ} \mathrm{C}\right) \sigma_{\mathrm{PC}}^{-1}$ for the Sahel, $0.57^{\circ} \mathrm{C}$ $\left(0.64^{\circ} \mathrm{C}\right) \sigma_{\mathrm{PC}}^{-1}$ for the $\mathrm{GC}$ region, and $0.34^{\circ} \mathrm{C}\left(0.34^{\circ} \mathrm{C}\right) \sigma_{\mathrm{PC}}^{-1}$ for GHA, estimated according to the statistical (dynamical) assessment. The statistical and dynamical assessments are in quantitative agreement, with an RMSE of $0.15^{\circ}, 0.09^{\circ}$, and $0.11^{\circ} \mathrm{C} \sigma_{\mathrm{PC}}^{-1}$ across the Sahel, GC region, and GHA, respectively, estimated using responses during the 11 nonhatched months. Both the statistical and dynamical assessments indicate that the TI1 mode mainly affects GHA temperature in CESM (Fig. 6f). The positive IOB mode, largely characterized by positive SST anomalies across Indian Ocean, supports higher air temperatures over GHA during early summer (June-July) by $0.17^{\circ} \mathrm{C}\left(0.13^{\circ} \mathrm{C}\right) \sigma_{\mathrm{PC}}^{-1}$, estimated by the statistical (dynamical) assessment. The positive IOD mode in CESM, with positive (negative) SST anomalies in the western (eastern) tropical Indian Ocean, reduces air temperature during autumn and early winter (SeptemberDecember) by about $-0.23^{\circ} \mathrm{C}\left(-0.21^{\circ} \mathrm{C}\right) \sigma_{\mathrm{PC}}^{-1}$, according to the statistical (dynamical) assessment. The RMSE is $0.07^{\circ} \mathrm{C} \sigma_{\mathrm{PC}}^{-1}$ for GHA. The inconsistency in 2-m air temperature responses to TI1 between the statistical and dynamical assessments in February and March is discussed in the supplemental material. Both assessments indicate weak responses in air temperature to TA1 forcing (Figs. 6g-i). The statistical assessments match the dynamical assessment, with RMSE of $0.02^{\circ}, 0.03^{\circ}$, and $0.05^{\circ} \mathrm{C} \sigma_{\mathrm{PC}}^{-1}$ for the Sahel, the GC region, and GHA, respectively.

As with the response in air temperature, $84 \%$ of precipitation responses are consistent between the two 
TP1

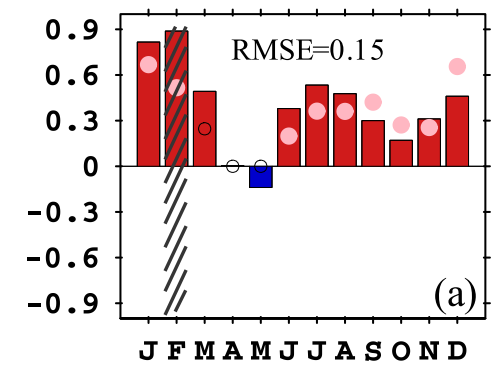

Sahel

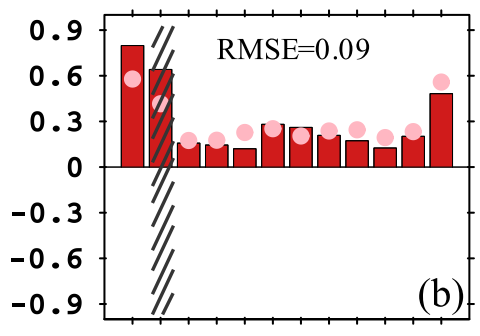

J F M A M J J A S O N D

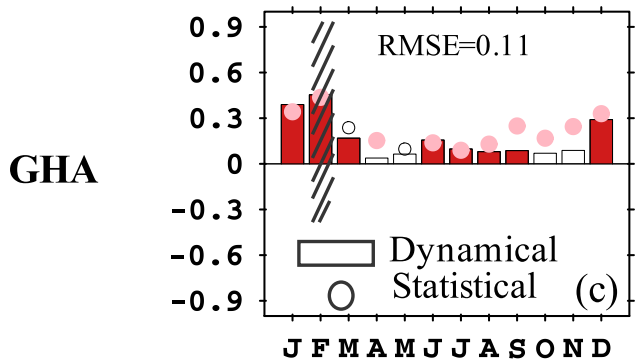

TI1

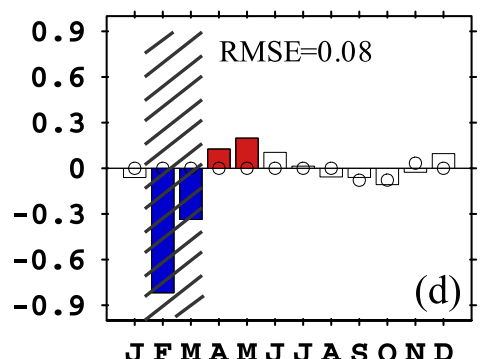

J F M A M J J A S O N D

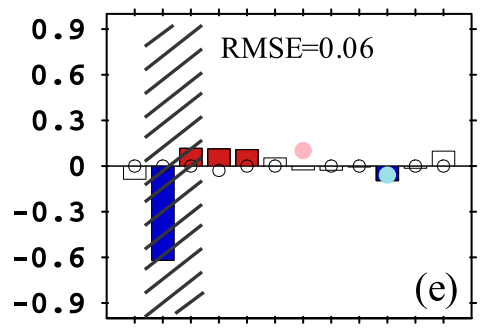

J F M A M J J A S O N D

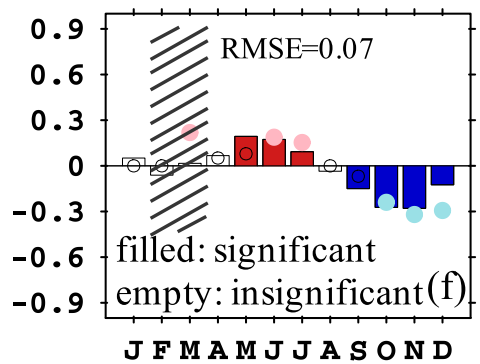

TA1
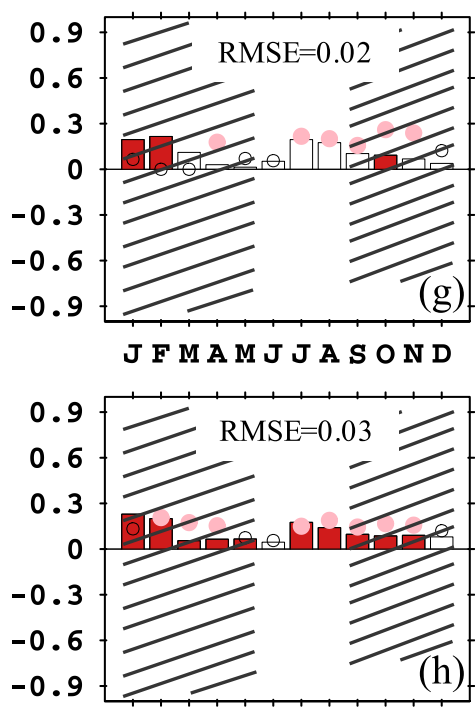

J F M A M J J A S O N D

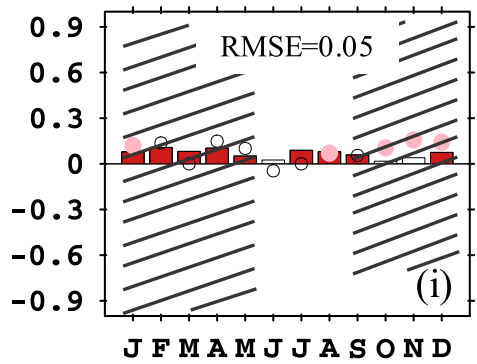

FIG. 6. Seasonal cycle of 2-m air temperature response $\left({ }^{\circ} \mathrm{C} \sigma_{\mathrm{PC}}^{-1}\right)$ to (a)-(c) TP1, (d)-(f) TI1, and (g)-(i) TA1 over the (top) Sahel, (middle) GC region, and (bottom) GHA in CESM. Bars and dots indicate responses according to the dynamic experiments and statistical SGEFA, respectively. Filled bars and dots indicate that the responses are statistically significant $(95 \%+)$ based on the Student's $t$ test (dynamic experiments) and Monte Carlo bootstrapping method (SGEFA), respectively. The inconsistent surface air temperature response to TI1 between dynamical and statistical assessment is caused by high temporal correlation between TP1 and TI1 (hatching area). The difference between statistical and dynamical assessments is measured by RMSE, excluding the hatched month $\left({ }^{\circ} \mathrm{C} \sigma_{\mathrm{PC}}^{-1}\right)$.

assessments in terms of significance and sign. Both statistical and dynamical assessments agree that El Niño reduces rainfall during July-September across all three NTA subregions (Figs. 7a-c), with decreases of $-0.18(-0.38)$ for the Sahel, $-0.17(-0.30)$ for the GC region, and $-0.27(-0.30) \mathrm{mm} \mathrm{day}^{-1} \sigma_{\mathrm{PC}}^{-1}$ for GHA, estimated by the statistical (dynamical) assessment. The yearly RMSE (without February) in the rainfall responses to TP1 between assessments is $0.18,0.19$, and $0.14 \mathrm{~mm}_{\text {day }}{ }^{-1} \sigma_{\mathrm{PC}}^{-1}$ over the Sahel, GC region, and GHA, respectively. Both statistical and dynamical assessments agree that the TI1 mode mainly affects GHA rainfall in CESM, making the GHA wetter almost all year round during positive TI1 mode, especially during the short rains season (OND; Fig. 7f). The precipitation response during OND is $0.76(0.78) \mathrm{mm} \mathrm{day}^{-1} \sigma_{\mathrm{PC}}^{-1}$ according to the statistical (dynamical) method. The yearly RMSE (excluding February-March) in the rainfall responses to TI1 between the statistical and dynamical assessments is $0.16 \mathrm{~mm} \mathrm{day}^{-1} \sigma_{\mathrm{PC}}^{-1}$. Both assessments conclude that the Atlantic Niño mode mainly regulates GC rainfall during the pre- and peakmonsoon seasons in CESM (Fig. 7h), with reduced rainfall $\left(-0.63\right.$ and $-0.47 \mathrm{~mm} \mathrm{day}^{-1} \sigma_{\mathrm{PC}}^{-1}$ according to statistical and dynamical assessments, respectively) in June and enhanced rainfall in July and August ( 0.44 and $0.55 \mathrm{~mm} \mathrm{day}^{-1} \sigma_{\mathrm{PC}}^{-1}$ according to statistical and dynamical methods, respctively). The 3-month (JJA) RMSE is $0.18 \mathrm{~mm} \mathrm{day}^{-1} \sigma_{\mathrm{PC}}^{-1}$.

In next section, the precipitation responses to TP1 in August, TI1 in June and November, and TA1 in June and August are examined as examples to compare the spatial patterns of response fields and related mechanisms. 
TP1

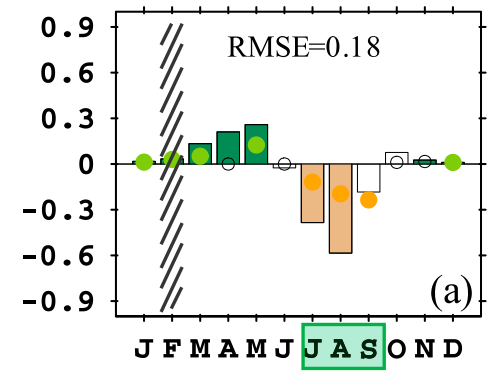

GC

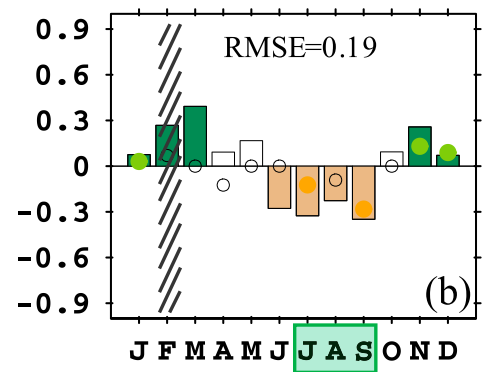

(b)

GHA

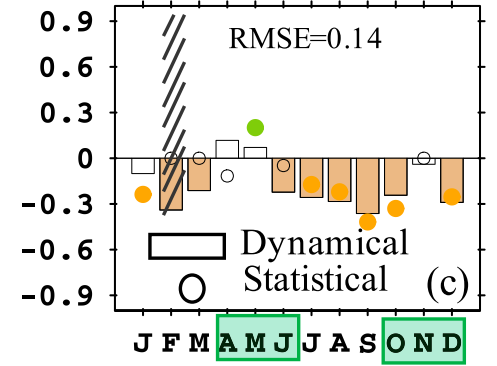

TI1
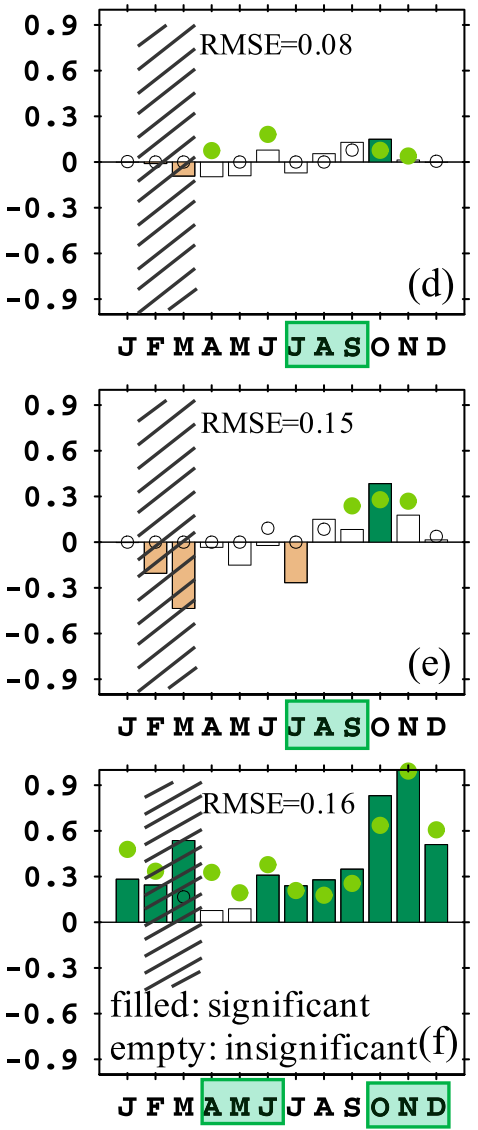

TA1
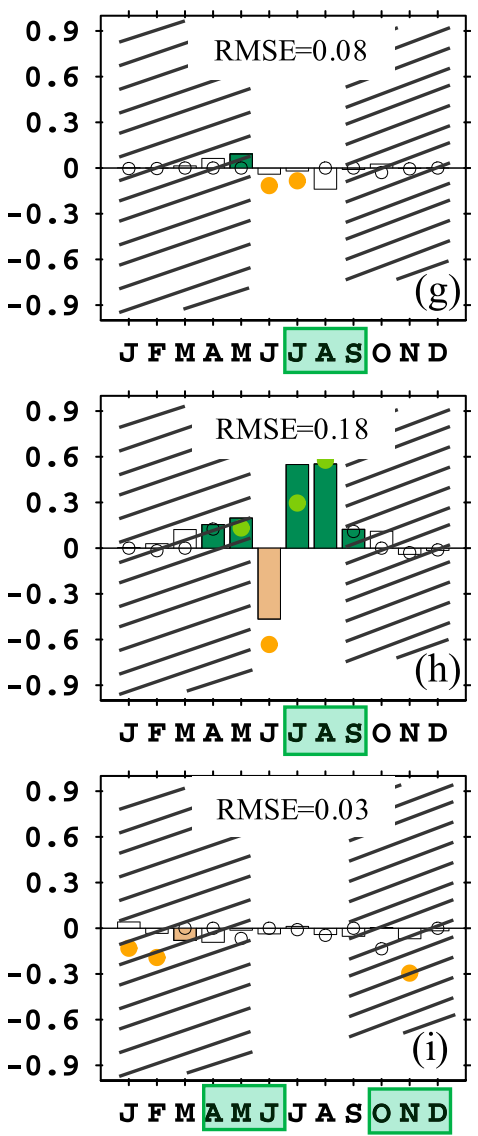

FIG. 7. As in Fig. 6, but for precipitation $\left(\mathrm{mm} \mathrm{day}^{-1} \sigma_{\mathrm{PC}}^{-1}\right)$. Green boxes on the $x$ axis indicate the wet seasons per region.

\section{d. Metric 4: Consistency in mechanisms}

\section{1) TP1: ENSO MODE}

In response to the positive phase of ENSO in boreal summer, both stepwise GEFA (Fig. 8a) and dynamic experiments (Fig. 8b) indicate a broad-scale reduction in rainfall over the tropical Atlantic Ocean (around $10^{\circ} \mathrm{N}$ ), extending partially over land into Sahel, the west side of the Ethiopian highlands, and into the western tropical Indian Ocean. The atmospheric response in August resembles a baroclinic Rossby wave response to deep tropical heating and barotropic Rossby wave propagation into the extratropics (Wen et al. 2010), here mainly confined to the Southern Hemisphere, given that it is austral winter (Figs. 8c-f). Anomalous low-level $(850 \mathrm{hPa})$ convergence and upperlevel $(200 \mathrm{hPa})$ divergence over the central and eastern tropical Pacific support an anomalously subsiding branch of the Walker circulation across NTA (Figs. 8a,b) that reduces precipitation, consistent with previous observational (Joly and Voldoire 2009; Preethi et al. 2015) and modeling studies (Giannini et al. 2003; Lu and Delworth 2005).

\section{2) TI1: IOB AND IOD MODES}

The TI1 mode, which represents the IOB (IOD) mode during February-July (August-January) in CESM, mainly affects rainfall over the GHA almost year-round, especially during the short rains season (OND) and the relatively dry summer season (June-September) between the long and short rains (Fig. 7f).

During June, both statistical and dynamical assessments agree that precipitation increases over the western slopes of the Ethiopian highlands (Figs. 9a,b) in response to positive phase of the IOB mode in CESM, characterized by warm water anomalies over most the tropical Indian Ocean, except for the southeast (Fig. 2g). Over the Indian Ocean, a Gill-type atmospheric response is induced (Gill 1980), with negative height anomalies in the lower troposphere ( $850 \mathrm{hPa}$; Figs. $9 \mathrm{c}, \mathrm{d})$ and positive height anomalies in the upper troposphere $(200 \mathrm{hPa}$; not shown). This anomalous low-level convergence over the tropical Indian 


\section{Atmospheric responses to ENSO mode in August}

Stepwise-GEFA

(a) Precip \& 500hPa $\omega$

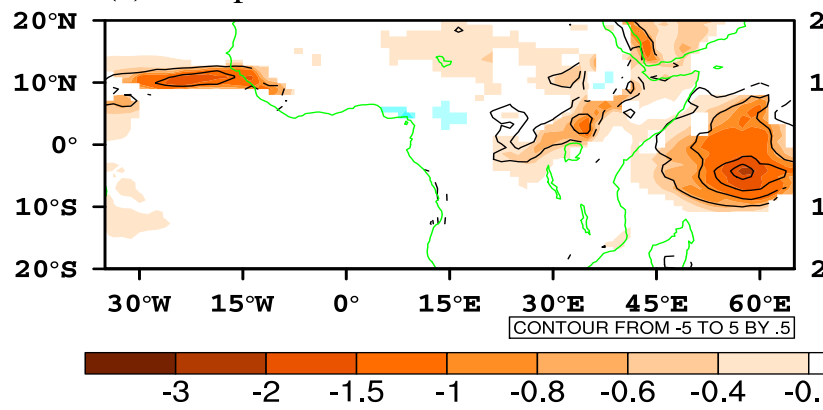

(c) $200 \mathrm{hPa} \mathrm{Z}, \mathrm{U}$, and $\mathrm{V}$

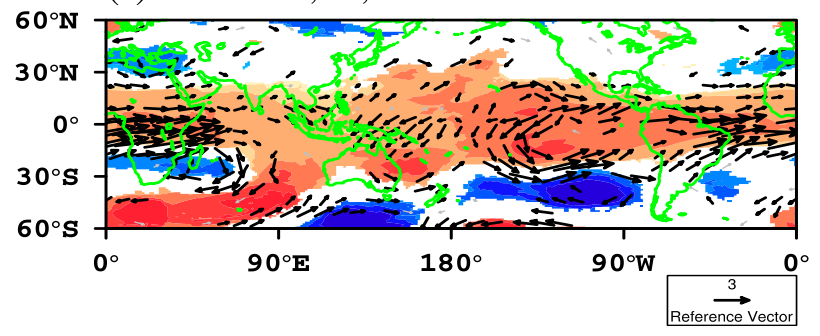

Dynamic experiments

(b) Precip \& 500hPa $\omega$

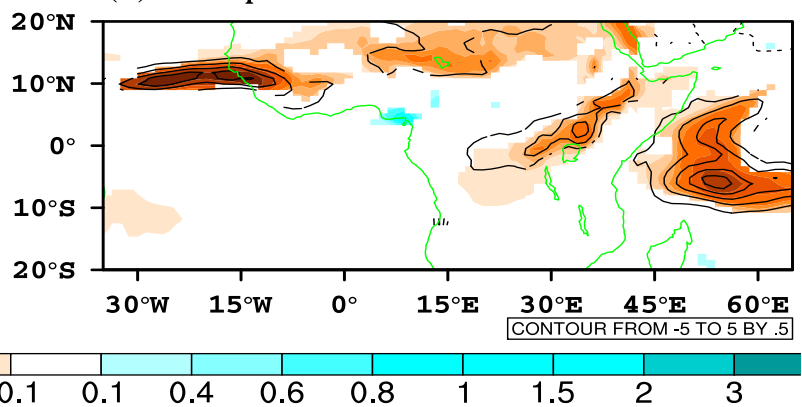

(d) $200 \mathrm{hPa} \mathrm{Z,} \mathrm{U,} \mathrm{and} \mathrm{V}$

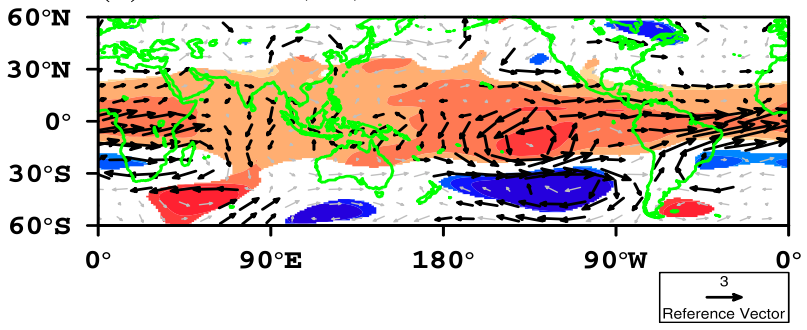

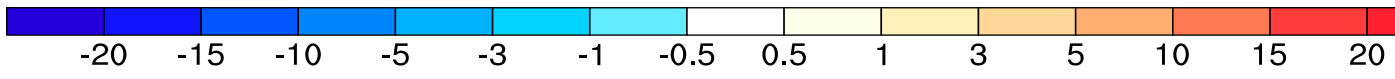

(e) $850 \mathrm{hPa} \mathrm{Z}, \mathrm{U}$, and $\mathrm{V}$

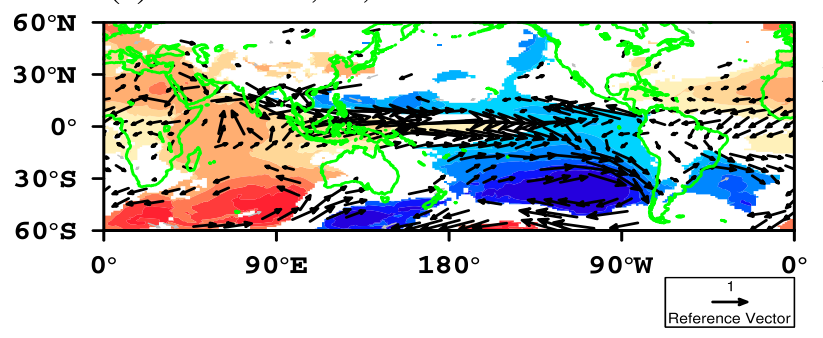

(f) $850 \mathrm{hPa} \mathrm{Z,} \mathrm{U,} \mathrm{and} \mathrm{V}$

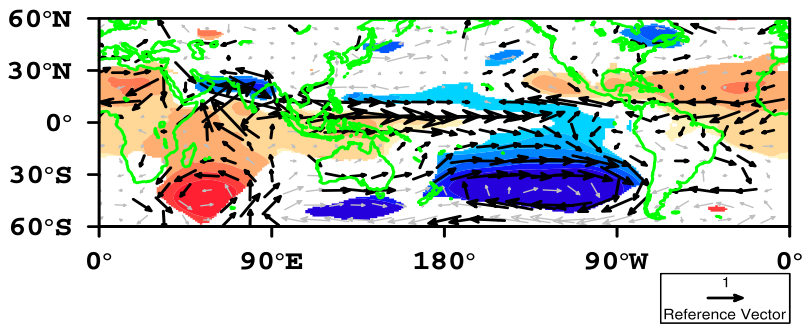

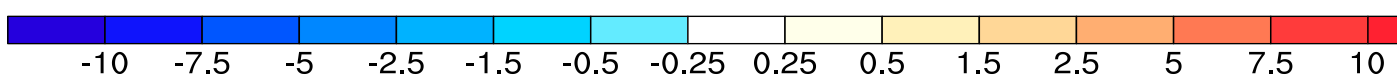

FIG. 8. Atmospheric responses to TP1 forcing (resembles Fig. 2c) using (a),(c),(e) stepwise GEFA and (b),(d),(f) dynamical assessment in August for CESM. Atmospheric response fields are (a),(b) precipitation (shading; $\mathrm{mm}^{\text {day }}{ }^{-1} \sigma_{\mathrm{PC}}^{-1}$ ) and $\omega 500$ (contour; hPa s ${ }^{-1} \sigma_{\mathrm{PC}}^{-1}$; solid lines indicate descending motion and dashed lines indicate ascending motion) and (c),(d) Z200 and (e),(f) Z850 (m $\left.\sigma_{\mathrm{PC}}^{-1}\right)$ and wind (gray vectors; $\left.\mathrm{m} \mathrm{s}^{-1} \sigma_{\mathrm{PC}}^{-1}\right)$. Only statistical significant $(>95 \%)$ response fields are shown except for wind field, where black arrows represent significant wind responses.

Ocean supports an increase in over-ocean precipitation. Meanwhile, the enhanced condensation and overland rainfall is attributed to westerly wind anomalies and resulting orographic lift over the Ethiopian highlands. Using observational data, Preethi et al. (2015) also concluded that the IOB mode can boost rainfall over the GHA region, although the IOB mode in observations exists during January - May compared to February-July in CESM.
During the short rains season, including November, both statistical and dynamical assessments indicate enhanced precipitation over the entire GHA (Figs. 10a,b) in response to the positive phase of the IOD mode in CESM, with positive SST anomalies over the western tropical Indian Ocean and negative SST anomalies over the eastern tropical Indian Ocean (Fig. 2h). There are two explanations for this enhanced precipitation over the GHA. First, positive SST anomalies across the western 


\section{Atmospheric responses to the IOD mode in June}

Stepwise-GEFA

(a) Precip \& 500hPa $\omega$

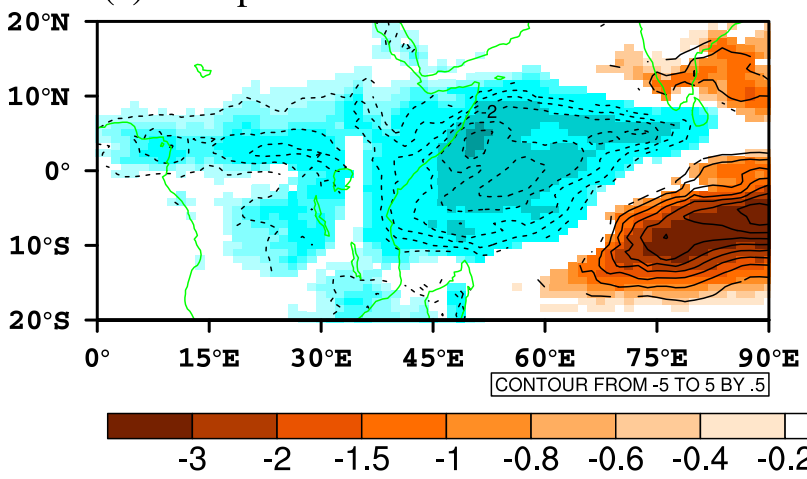

(c) $850 \mathrm{hPa}$ wind \& moisture divergence
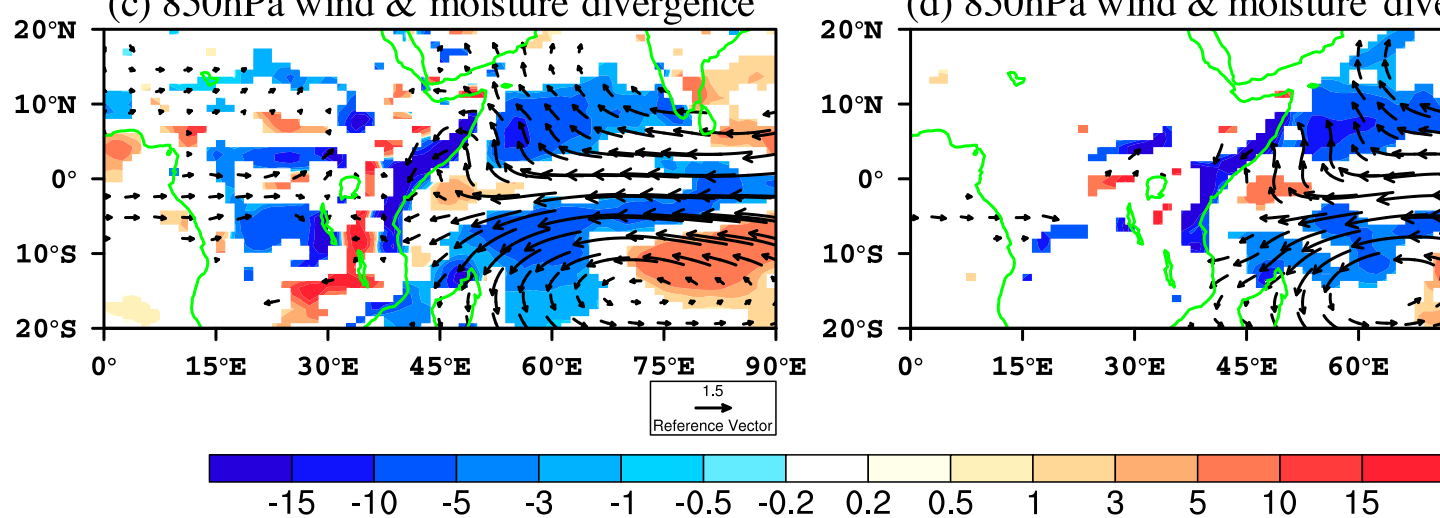

Dynamic experiments

(b) Precip \& 500hPa $\omega$

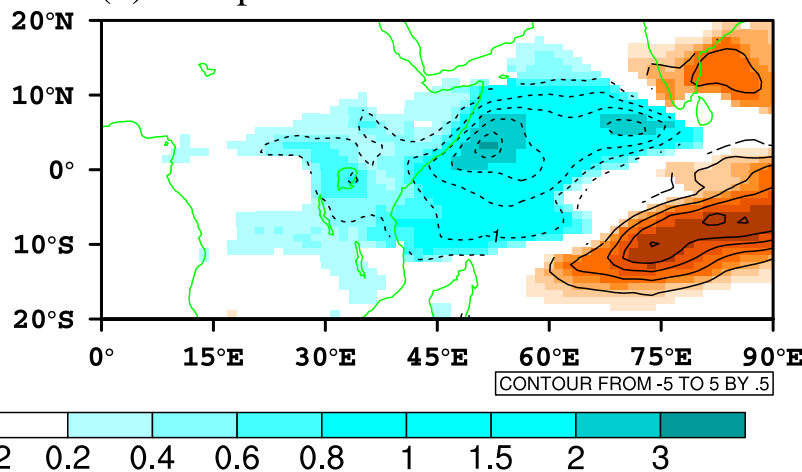

(d) $850 \mathrm{hPa}$ wind \& moisture divergence

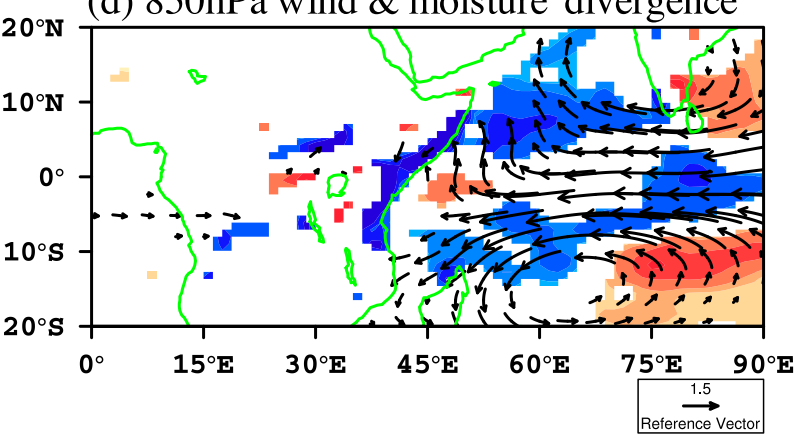

FIG. 9. Precipitation (shading; $\mathrm{mm} \mathrm{day}{ }^{-1} \sigma_{\mathrm{PC}}^{-1}$ ) and $\omega 500$ (contour; hPa s${ }^{-1} \sigma_{\mathrm{PC}}^{-1}$ ) responses to TI1 forcing (resembles Fig. $2 \mathrm{~g}$ ) using (a) SGEFA and (b) dynamic experiment during June for CESM. Moisture divergence at $850 \mathrm{hPa}$ (shading; $10^{-6} \mathrm{~m} \mathrm{~s}{ }^{-1} \sigma_{\mathrm{PC}}^{-1}$ ) and $850-\mathrm{hPa}$ wind response (vector; $\mathrm{m} \mathrm{s}^{-1} \sigma_{\mathrm{PC}}^{-1}$ ) to TI1 forcing using (c) SGEFA and (d) dynamic experiments. Only statistical significant response $(>95 \%)$ fields are shown.

tropical Indian Ocean increase air temperature, atmospheric moisture, and instability. Second, as in June, enhanced convergence over the anomalously warm waters of the western tropical Indian Ocean generate westerly wind anomalies over western and central Africa and easterly wind anomalies over the Indian Ocean. The zonally oriented SST gradient enhances the zonal surface pressure gradient, leading to stronger easterly winds, which brings more moisture to Somalia than in June. Enhanced atmospheric moisture and wind convergence support an increase in GHA rainfall. Ummenhofer et al. (2009) also found that the local positive SST anomalies over the western Indian Ocean can enhance precipitation over the GHA during its short rain season, although they consider the corresponding cold anomalies over the eastern Indian Ocean to be unimportant.
The statistical and dynamical assessments generally agree in terms of both the spatial pattern in atmospheric response fields and related mechanisms. The slightly disagreement in precipitation and vertical motion response to TI1 in June (Figs. 9a,b) and November (Figs. 10a,b) to the west of $30^{\circ} \mathrm{E}$ may be caused by the nonlinear atmospheric response to TI1, since stepwise GEFA estimates the feedback using the forcing strength that covers the full spectrum found in the CTL run, while the dynamical assessments estimate the feedback response to one standard deviation anomalies of TI1.

\section{3) TA1: ATLANTIC NiÑO MODE}

In CESM, both statistical and dynamical assessments indicate that the Atlantic Niño mode mainly regulates rainfall over the GC region during the pre- and 


\section{Atmospheric responses to the IOB mode in November}

Stepwise-GEFA

(a) Precip \& 500hPa $\omega$

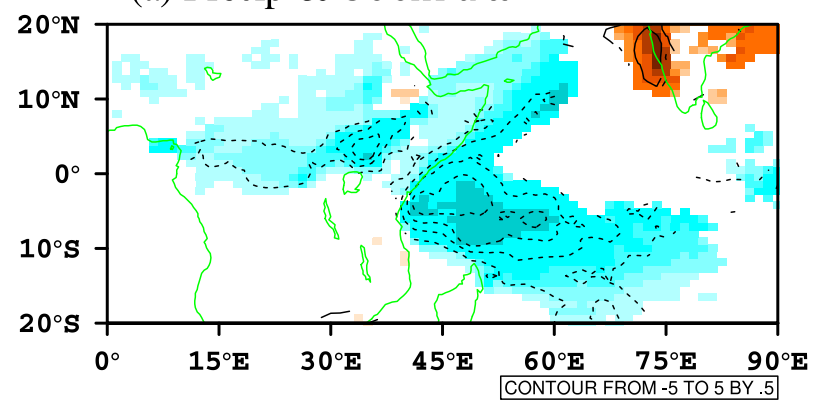

Dynamic experiments

(b) Precip \& 500hPa $\omega$

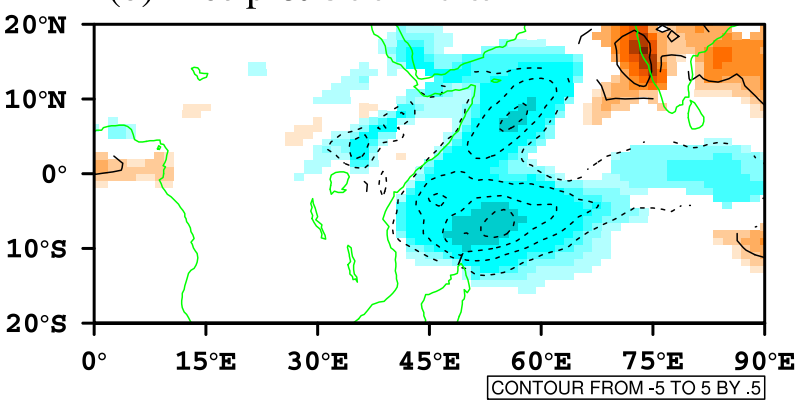

\begin{tabular}{lll|l|l|ll|l|l|l}
\hline & $\mid$ & & & & & & $\mid$ & $\mid$ \\
-3 & -2 & -1.5 & -1 & -0.8 & -0.6 & -0.4 & -0.2
\end{tabular}

(c) $850 \mathrm{hPa}$ wind \& moisture divergence
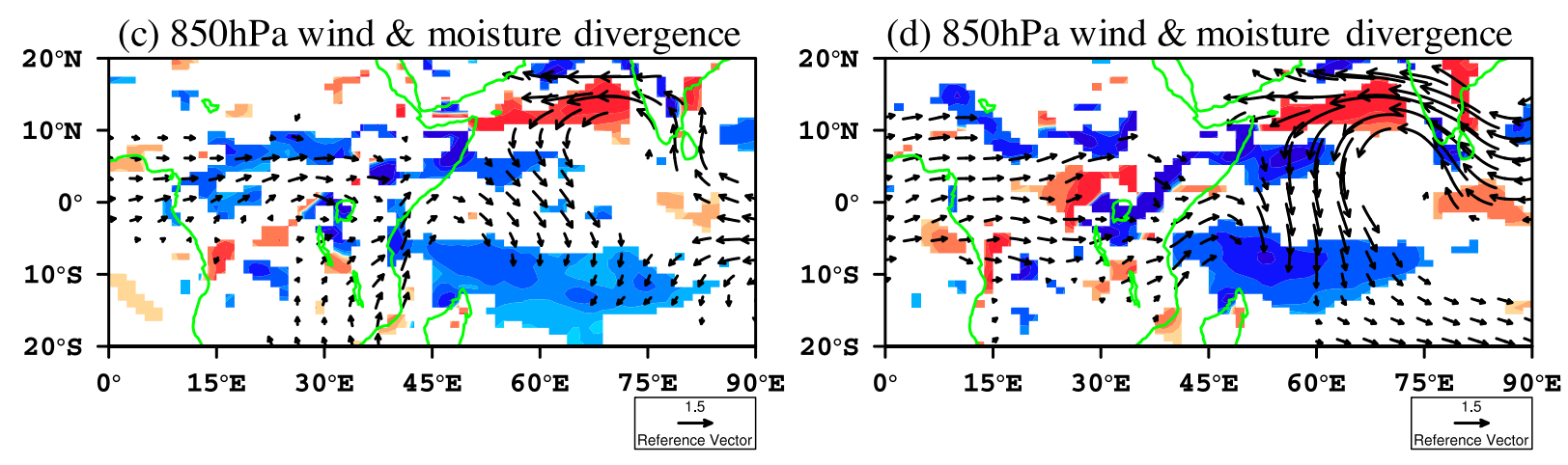

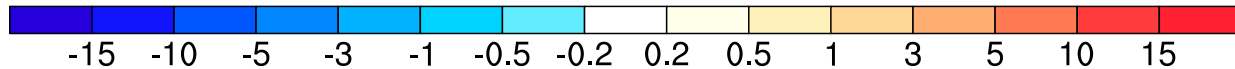

FIG. 10. As in Fig. 9, but for November. The TI1 forcing resembles that shown in Fig. 2h.

peak-monsoon seasons in CESM (Fig. 7h), specifically reducing rainfall in June, while enhancing rainfall in JulyAugust.

In June, the climatological location of the ITCZ, based on the minimum value of outgoing longwave radiation (OLR), is $4^{\circ} \mathrm{N}$ in CESM (black dashed line in Fig. 11a). The positive SST anomalies associated with the Atlantic Niño mode lie along the southern flank of the ITCZ (Fig. 11a). Both statistical and dynamical assessments indicate that the anomalously warm eastern tropical Atlantic Ocean favors a southward shift of the ITCZ and its associated ascent. Anomalous low-level moisture convergence (Fig. 11d) is produced near the equator, leading to greater precipitation to the south of the Gulf of Guinea and extending westward into the tropical Atlantic Ocean. Accompanying the southwardshifted ITCZ, anomalous descending motion emerges just north of the anomalous ascending motion band. A belt of anomalous moisture divergence is generated from the Gulf of Guinea into the tropical Atlantic
Ocean, resulting in reduced precipitation over the GC region.

In August (similar to July), the climatological location of the Atlantic ITCZ is around $10^{\circ} \mathrm{N}$ in CESM, with a positive TA1 mode characterized by anomalously warm waters to the south and cold waters to the north of the climatological ITCZ (Fig. 12a). The warmer eastern tropical Atlantic Ocean still favors a southward shifted ITCZ. However, distinct from June, the belt of anomalous moisture convergence and corresponding ascending motion lies over the GC region, with anomalous descending motion confined to the north over the tropical Atlantic Ocean (Figs. 12b,c). The moisture convergence over the GC region strengthens the West African monsoon flow and enhances precipitation.

The statistical and dynamical assessments agree well in terms of both the spatial pattern in atmospheric response fields and related mechanisms. Both methods capture the unique precipitation response to TA1 forcing during June versus July-August over the GC region, 


\section{Atmospheric responses to the Atlantic Niño mode in June}

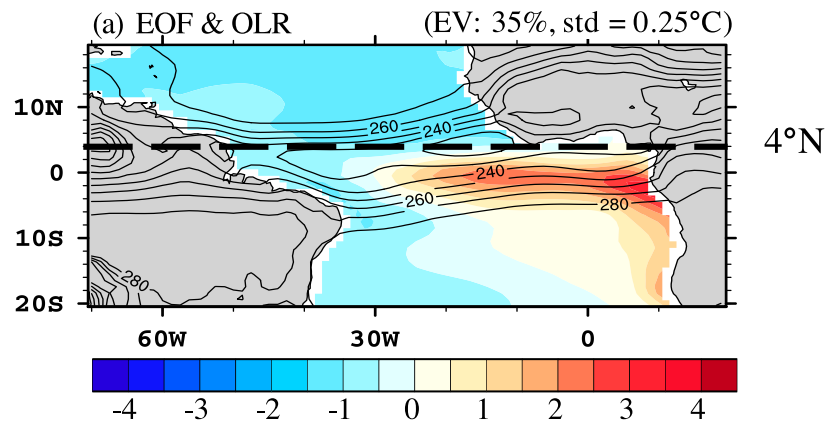

Stepwise-GEFA

(b) Precip \& 500hPa $\omega$

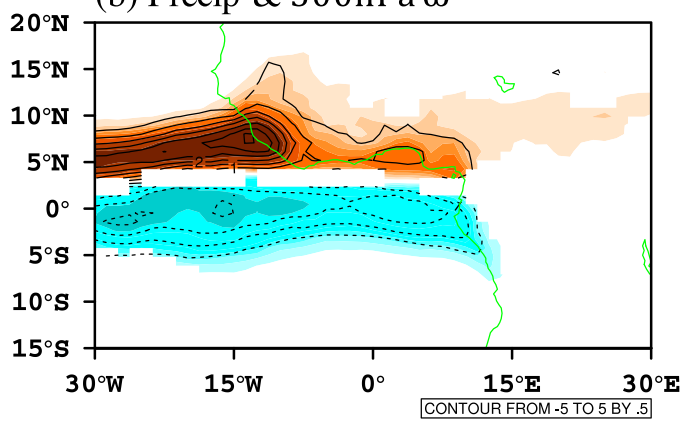

Dynamic experiments

(c) Precip \& 500hPa $\omega$

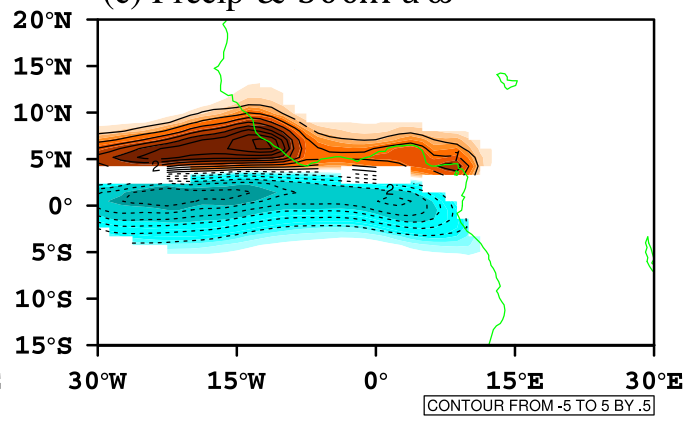

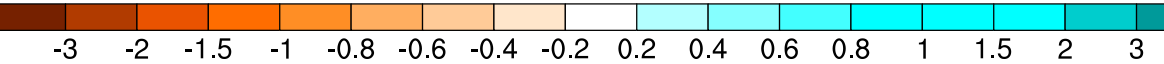

(d) $850 \mathrm{hPa}$ wind $\&$ moisture divergence

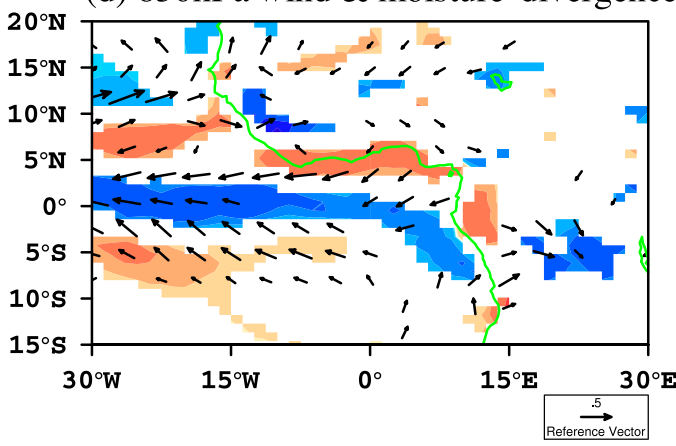

(e) $850 \mathrm{hPa}$ wind \& moisture divergence
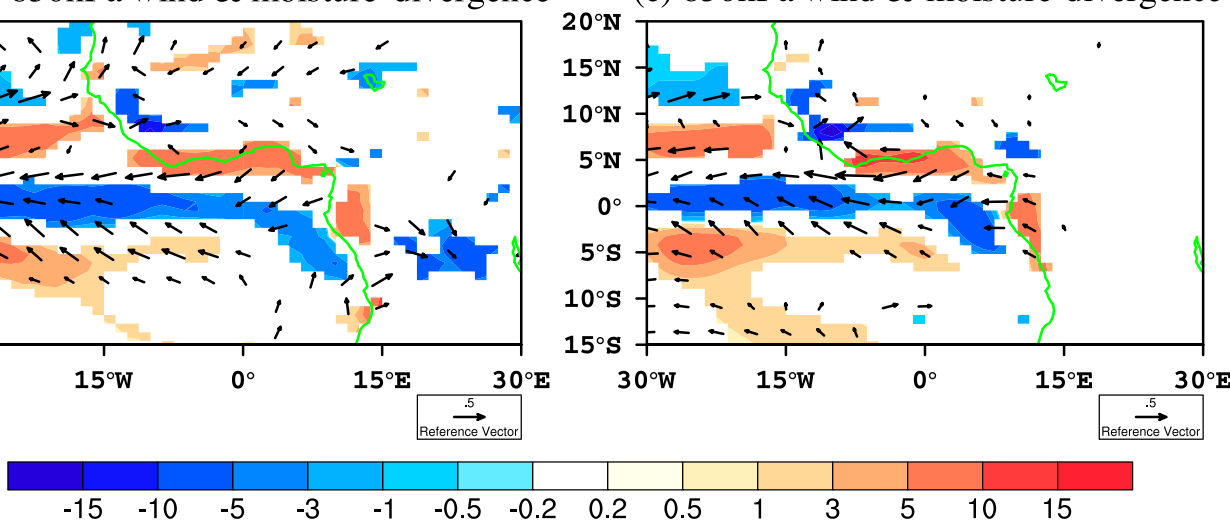

FIG. 11. (a) Climatological OLR (contour; $\mathrm{W} \mathrm{m}^{-2}$ ) and leading EOF of SST over the tropical Atlantic Ocean based on 300-yr control run for June in CESM. The magnitude of the spatial pattern is normalized with a standard deviation of $1{ }^{\circ} \mathrm{C}$. The explained variance (EV) and standard deviation (std) of corresponding principal components are indicated in parentheses. Also shown are precipitation (shading; $\mathrm{mm} \mathrm{day}^{-1} \sigma_{\mathrm{PC}}^{-1}$ ) and $\omega 500$ (contour; $\mathrm{hPa} \mathrm{s}^{-1} \sigma_{\mathrm{PC}}^{-1}$ ) response to TA1 forcing using (b) SGEFA and (c) dynamic experiments during June, and 850-hPa moisture divergence (shading; $10^{-6} \mathrm{~m} \mathrm{~s}^{-1} \sigma_{\mathrm{PC}}^{-1}$ ) and $850-\mathrm{hPa}$ wind response (vector; $\mathrm{m} \mathrm{s}^{-1} \sigma_{\mathrm{PC}}^{-1}$ ) for TA1 forcing using (d) SGEFA and (e) dynamic experiments. Only statistical significant response ( $>95 \%$ ) fields are shown.

because of the climatological latitudinal position of the Atlantic ITCZ.

Our CESM results are consistent with previous modeling studies in terms of the reduced rainfall response in June and enhanced rainfall response in July to the TA1 forcing. By holding equatorial Atlantic SST to its April climatological value, Okumura and Xie (2004) concluded that ocean surface cooling in the eastern tropical Atlantic Ocean leads to a dipole precipitation response with declines over the tropical Atlantic and Guinea 


\section{Atmospheric responses to the Atlantic Niñno mode in August}

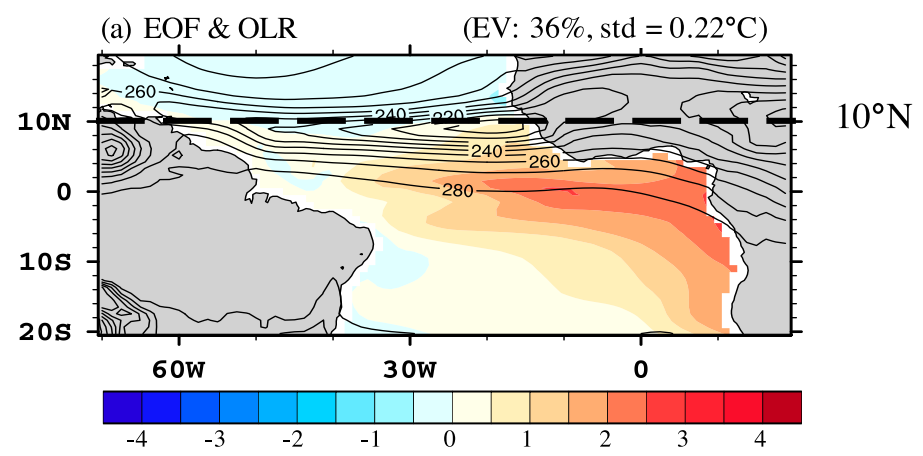

Stepwise-GEFA

(b) Precip \& 500hPa $\omega$

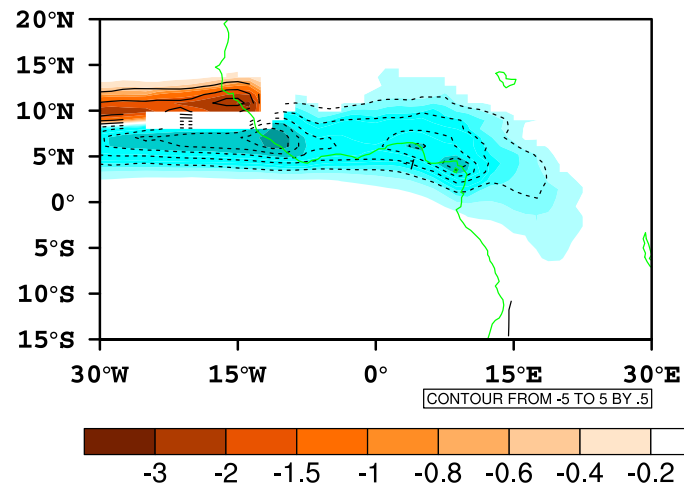

(d) $850 \mathrm{hPa}$ wind $\&$ moisture divergence

Dynamic experiments

(c) Precip \& 500hPa $\omega$

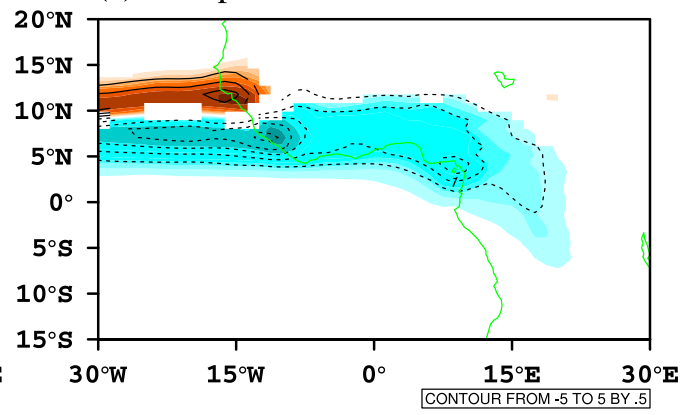

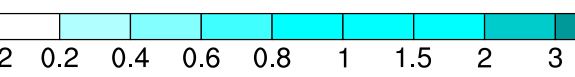

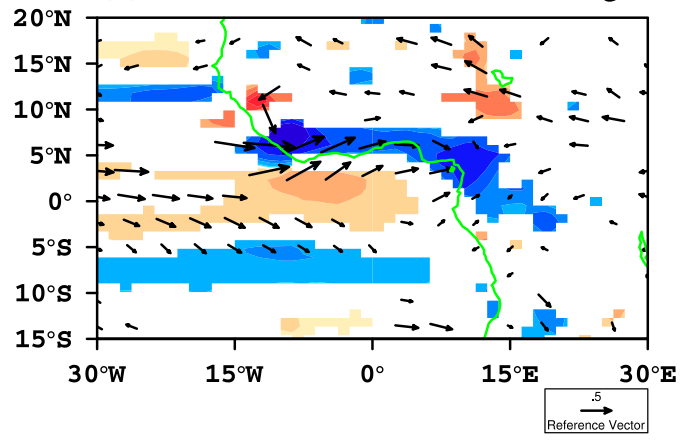

(e) $850 \mathrm{hPa}$ wind \& moisture divergence
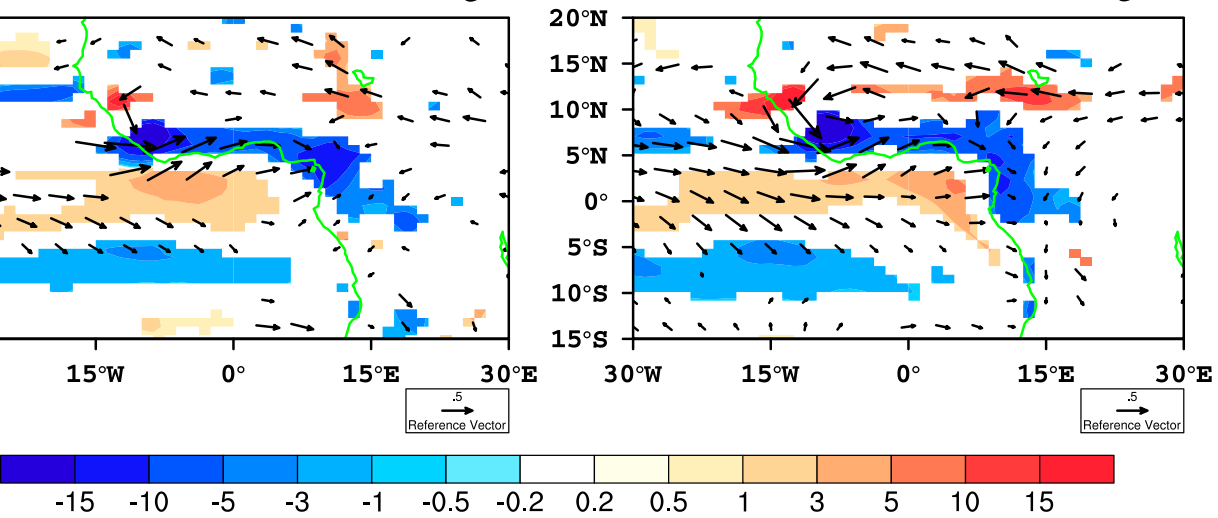

FIG. 12. As in Fig. 11, but for August.

Coast and increases over the tropical northern Atlantic and western Sahel in June. By adding a positive SST anomaly over the Gulf of Guinea in July, Vizy and Cook (2001) found enhanced rainfall over the Guinea Coast. The reversed precipitation response to the Atlantic Niño forcing by these two independent studies may also reflect the impact of the relative location of the ITCZ and the SST warming.

\section{Conclusions and discussion}

This study proposes an advanced GEFA statistical method, known as stepwise GEFA, and demonstrates its capability to successfully decompose the key oceanic drivers of regional climate using NCAR CESM, with a focus on northern and tropical Africa. Stepwise GEFA offers clear advantages over full GEFA in obtaining 
stable response fields. By dropping unimportant forcings from the forcing matrix through stepwise selection, sampling errors are reduced, allowing stepwise GEFA to more accurately capture the atmospheric response fields to oceanic forcing than full GEFA, especially when the available data record is short or highly correlated forcings exist in the forcing matrix.

Stepwise GEFA is validated by comparing statistical assessments of the CTL run against dynamical assessments of ensemble experiments (with imposed basinwide SST anomalies) based on four metrics: percentage of consistency, spatial correlation, seasonal cycle of response magnitude, and consistency in associated mechanisms. The average range of consistency and spatial correlation in atmospheric response fields is $67 \%-71 \%$ and $0.87-0.90$, respectively. The RMSE of seasonal response magnitude ranges between $0.03^{\circ}-0.12^{\circ} \mathrm{C} \sigma_{\mathrm{PC}}^{-1}$ for $2-\mathrm{m}$ air temperature and 0.10 $0.17 \mathrm{~mm} \mathrm{day}^{-1} \sigma_{\mathrm{PC}}^{-1}$ for precipitation averaged over three NTA subregions. The statistical and dynamical assessments agree well in terms of both the spatial pattern in atmospheric response fields and related mechanisms.

According to the statistical assessment, tropical modes are the most important oceanic drivers of NTA climate in CESM, namely ENSO and the IOB, IOD, and Atlantic Niño modes. Both statistical and dynamical assessments agree with the following statements. Sahel rainfall is mainly regulated by ENSO, with El Niño inducing drying of the Sahel during the peak monsoon season. In CESM, GHA precipitation is mainly affected by both the IOB (warm water anomaly over most of the tropical Indian Ocean) and IOD [positive (negative) SST anomalies over the western (eastern) tropical Indian Ocean] modes. Both oceanic forcings result in increased GHA rainfall mainly during the short rains and relative dry season of June-September. The GC rainfall is mainly influenced by Atlantic Niño mode, with precipitation decreasing in June and increasing in July and August.

Stepwise GEFA is a generalized method, applicable to other regions or other Earth system models. However, some caution is needed before utilizing stepwise GEFA in other regions. Stepwise GEFA is only suitable to extract responses in rapidly evolving atmospheric variables to slowly varying environmental variables, such as SST, sea ice fraction, snow cover fraction, and LAI. Therefore, the memory of the target variable should first be checked. When considering different regions and models than in the present study, it should be recognized that the dominant forcings may be different, so the minimum required data length should be examined to make sure that the stepwise GEFA pattern is stable and reliable. If highly correlated coexisting forcings are included in the forcing matrix, we suggest comparing their combined impacts with their individual impacts to avoid artificial responses.

This study is one of a series of papers. The stepwise GEFA's reliability at capturing the impacts of terrestrial forcings on the regional climate of the Sahel and GC region is examined in $\mathrm{Yu}$ et al. (2017, manuscript submitted to Nat. Commun.). Then, following the successful validation of stepwise GEFA across northern and tropical Africa for both oceanic and terrestrial forcings in the current paper and that of Yu et al. (2017, manuscript submitted to Nat. Commun.) the statistical method is applied to investigate observed vegetationclimate feedbacks in the Sahel by Yu et al. (2017, manuscript submitted to J. Climate). In future applications, stepwise GEFA will be used to evaluate both oceanic and terrestrial impacts on NTA climate in CMIP5 models compared to a GEFA-based observational benchmark, and those models can accurately reproduce both the observed oceanic and terrestrial drivers and their impacts on NTA climate will be assigned greater weights, leading to process-based weighting of climate change projections for the region.

Acknowledgments. This work is funded by U.S. Department of Energy (DOE) Regional and Global Climate Modeling (RGCM) Program (Grant PRJ88SM) and National Science Foundation (NSF) Climate and Large-Scale Dynamics (CLD) Program (Grant 1343904). Computer resources are provided by DOE National Energy Research Scientific Computing Center (NERSC) and National Science Foundation Computational Information Systems Laboratory Yellowstone (NSF/ CISL/Yellowstone). We also acknowledge the CESM Large Ensemble Community Project. We also thank two anonymous reviewers for their excellent suggestions and comments.

\section{REFERENCES}

Akaike, H., 1974: A new look at the statistical model identification. IEEE Trans. Automat. Control, 19, 716-723, doi:10.1109/ TAC.1974.1100705.

Biasutti, M., and A. Giannini, 2006: Robust Sahel drying in response to late 20th century forcings. Geophys. Res. Lett., 33, L11706, doi:10.1029/2006GL026067.

Black, E., J. Slingo, and K. R. Sperber, 2003: An observational study of the relationship between excessively strong short rains in coastal East Africa and Indian Ocean SST. Mon. Wea. Rev., 131, 74-94, doi:10.1175/1520-0493(2003)131<0074: AOSOTR $>2.0 . \mathrm{CO} ; 2$.

Camberlin, P., S. Janicot, and I. Poccard, 2001: Seasonality and atmospheric dynamics of the teleconnection between African rainfall and tropical sea-surface temperature: Atlantic vs. ENSO. Int. J. Climatol., 21, 973-1005, doi:10.1002/joc.673. 
Czaja, A., and C. Frankignoul, 2002: Observed impact of Atlantic SST anomalies on the North Atlantic Oscillation. J. Climate, 15, 606-623, doi:10.1175/1520-0442(2002)015<0606: OIOASA $>2.0 . \mathrm{CO} ; 2$.

Few, R., M. Ahern, F. Matthies, and S. Kovats, 2004: Floods, health and climate change: A strategic review. Tyndall Centre for Climate Change Research working paper, 138 pp.

Folland, C. K., T. N. Palmer, and D. E. Parker, 1986: Sahel rainfall and worldwide sea temperatures, 1901-85. Nature, 320, 602607, doi:10.1038/320602a0.

Frankignoul, C., and K. Hasselmann, 1977: Stochastic climate models, Part II: Application to sea surface temperature anomalies and thermocline variability. Tellus, 29, 289-305, doi:10.3402/tellusa.v29i4.11362.

_- N. Chouaib, and Z. Liu, 2011: Estimating the observed atmospheric response to SST anomalies: Maximum covariance analysis, generalized equilibrium feedback assessment, and maximum response estimation. J. Climate, 24, 2523-2539, doi:10.1175/2010JCLI3696.1.

Gaetani, M., B. Fontaine, P. Roucou, and M. Baldi, 2010: Influence of the Mediterranean Sea on the West African monsoon: Intraseasonal variability in numerical simulations. J. Geophys. Res., 115, D24115, doi:10.1029/2010JD014436.

Gautam, M., 2006: Managing drought in Sub-Sahara Africa: Policy perspectives. IAAE Conf., Gold Coast, Queensland, Australia, International Association of Agricultural Economists. [Available online at http://purl.umn.edu/25608.]

Giannini, A., R. Saravanan, and P. Chang, 2003: Oceanic forcing of Sahel rainfall on interannual to interdecadal time scales. Science, 302, 1027-1030, doi:10.1126/science.1089357.

— S. Salack, T. Londoun, A. Ali, A. T. Gaye, and O. Ndiaye, 2013: A unifying view of climate change in the Sahel linking intra-seasonal, interannual and longer time scales. Environ. Res. Lett., 8, 024010, doi:10.1088/1748-9326/8/2/024010.

Gill, A. E., 1980: Some simple solutions for heat-induced tropical circulation. Quart. J. Roy. Meteor. Soc., 106, 447-462, doi:10.1002/qj.49710644905.

Hasselmann, K., 1976: Stochastic climate models: Part I. Theory. Tellus, 28, 473-485, doi:10.3402/tellusa.v28i6.11316.

Hocking, R. R., 1976: The analysis and selection of variables in linear regression. Biometrics, 32, 1-49, doi:10.2307/2529336.

Hoerling, M., J. Hurrell, J. Eischeid, and A. Phillips, 2006: Detection and attribution of twentieth-century northern and southern African rainfall change. J. Climate, 19, 3989-4008, doi:10.1175/JCLI3842.1.

Hoffman, F. M., and Coauthors, 2008: The Carbon-Land Model Project (C-LAMP): A protocol and evaluation metrics for global terrestrial biogeochemistry models. Fourth Int. Congress on Environmental Modeling and Software, Barcelona, Spain, International Congress on Environmental Modeling and Software. [Available online at http://scholarsarchive.byu. edu/iemssconference/2008/all/245.]

Hunke, E. C., W. H. Lipscomb, A. K. Turner, N. Jeffery, and S. Elliott, 2008: CICE: The Los Alamos sea ice model, documentation and software, version 4.0. Los Alamos National Laboratory Tech. Rep. LA-CC-06-012, 116 pp. [Available online at oceans11.lanl.gov/trac/CICE/raw-attachment/wiki/ WikiStart/cicedoc.pdf.]

Hurrell, J. W., and Coauthors, 2013: The Community Earth System Model: A framework for collaborative research. Bull. Amer. Meteor. Soc., 94, 1339-1360, doi:10.1175/BAMS-D-12-00121.1.

Indeje, M., F. H. M. Semazzi, and L. J. Ogallo, 2000: ENSO signals in East African rainfall seasons. Int. J. Climatol.,
20, 19-46, doi:10.1002/(SICI)1097-0088(200001)20:1<19:: AID-JOC449>3.0.CO;2-0.

Janicot, S., S. Trzaska, and I. Poccard, 2001: Summer Sahel-ENSO teleconnection and decadal time scale SST variations. Climate Dyn., 18, 303-320, doi:10.1007/s003820100172.

Joly, M., and A. Voldoire, 2009: Influence of ENSO on the West African monsoon: Temporal aspects and atmospheric processes. J. Climate, 22, 3193-3210, doi:10.1175/2008JCLI2450.1.

,,-- H. Douville, P. Terray, and J.-F. Royer, 2007: African monsoon teleconnections with tropical SSTs: Validation and evolution in a set of IPCC4 simulations. Climate Dyn., 29, 1-20, doi:10.1007/s00382-006-0215-8.

Jung, T., L. Ferranti, and A. M. Tompkins, 2006: Response to the summer of 2003 Mediterranean SST anomalies over Europe and Africa. J. Climate, 19, 5439-5454, doi:10.1175/JCLI3916.1.

Kay, J. E., and Coauthors, 2015: The Community Earth System Model (CESM) large ensemble project: A community resource for studying climate change in the presence of internal climate variability. Bull. Amer. Meteor. Soc., 96, 1333-1349, doi:10.1175/BAMS-D-13-00255.1.

Klein, S. A., B. J. Soden, and N.-C. Lau, 1999: Remote sea surface temperature variations during ENSO: Evidence for a tropical atmospheric bridge. J. Climate, 12, 917-932, doi:10.1175/ 1520-0442(1999)012<0917:RSSTVD>2.0.CO;2.

Lamb, P. J., 1978: Large-scale tropical Atlantic surface circulation patterns associated with sub-Saharan weather anomalies. Tellus, 30, 240-251, doi:10.3402/tellusa.v30i3.10338.

Lau, N.-C., A. Leetmaa, and M. J. Nath, 2006: Attribution of atmospheric variations in the 1997-2003 period to SST anomalies in the Pacific and Indian Ocean basins. J. Climate, 19, 3607-3628, doi:10.1175/JCLI3813.1.

Lawrence, D. M., and Coauthors, 2011: Parameterization improvements and functional and structural advances in version 4 of the Community Land Model. J. Adv. Model. Earth Syst., 3, M03001, doi:10.1029/2011MS00045.

Lee, J., and B. Wang, 2012: Seasonal climate prediction and predictability of atmospheric circulation. Climate Models, L. Druyan, Ed., InTech, 19-42, doi:10.5772/33782.

Liu, Z., M. Notaro, J. Kutzbach, and N. Liu, 2006: Assessing global vegetation-climate feedbacks from observation. J. Climate, 19, 787-814, doi:10.1175/JCLI3658.1.

— N. Nen, and Y. Liu, 2008: On the assessment of nonlocal climate feedback. Part I: The generalized equilibrium feedback assessment. J. Climate, 21, 134-148, doi:10.1175/ 2007JCLI1826.1.

$\longrightarrow, \ldots$, and L. Fan, 2012a: Assessing atmospheric response to surface forcing in the observations. Part I: Cross validation of annual response using GEFA, LIM, and FDT. J. Climate, 25, 6796-6816, doi:10.1175/JCLI-D-11-00545.1.

_ L L. Fan, S.-I. Shin, and Q. Liu, 2012b: Assessing atmospheric response to surface forcing in the observation. Part II: Cross validation of seasonal response using GEFA and LIM. J. Climate, 25, 6817-6834, doi:10.1175/JCLI-D-11-00630.1.

Loewenberg, S., 2011: Humanitarian response inadequate in Horn of Africa crisis. Lancet, 378, 555-558, doi:10.1016/ S0140-6736(11)61276-2.

Losada, T., B. Rodríguez-Fonseca, E. Mohino, J. Bader, S. Janicot, and C. R. Mechoso, 2012: Tropical SST and Sahel rainfall: A non-stationary relationship. Geophys. Res. Lett., 39, L12705, doi:10.1029/2012GL052423.

Lu, J., and T. L. Delworth, 2005: Oceanic forcing of the late 20th century Sahel drought. Geophys. Res. Lett., 32, L22706, doi:10.1029/2005GL023316. 
Neale, R. B., and Coauthors, 2010: Description of the NCAR Community Atmosphere Model (CAM5.0). NCAR Tech. Note NCAR/TN-486+STR, 268 pp. [Available online at www.cesm. ucar.edu/models/cesm1.1/cam/docs/description/cam5_desc.pdf.]

Newman, M., G. Compo, and M. Alexander, 2003: ENSOforced variability of the Pacific decadal oscillation. J. Climate, 16, 3853-3857, doi:10.1175/1520-0442(2003)016<3853: EVOTPD $>2.0 . \mathrm{CO} ; 2$.

Nicholson, S. E., 2000: The nature of rainfall variability over Africa on time scales of decades to millennia. Global Planet. Change, 26, 137-158, doi:10.1016/S0921-8181(00)00040-0.

_ 2013: The West African Sahel: A review of recent studies on the rainfall regime and its interannual variability. ISRN Meteor., 2013, 453521, doi:10.1155/2013/453521.

Notaro, M., Z. Liu, and J. W. Williams, 2006: Observed vegetationclimate feedbacks in the United States. J. Climate, 19, 763-786, doi:10.1175/JCLI3657.1.

Okumura, Y., and S.-P. Xie, 2004: Interaction of the Atlantic equatorial cold tongue and the African monsoon. J. Climate, 17, 3589-3602, doi:10.1175/1520-0442(2004)017<3589:IOTAEC >2.0.CO;2.

Oleson, K. W., and Coauthors, 2010: Technical description of version 4.0 of the Community Land Model (CLM). NCAR Tech. Note NCAR/TN-478+STR, 266 pp.

Opio-Odongo, J., 2014: Africa Environment Outlook 3: Our Environment, Our Health. United Nations, $256 \mathrm{pp}$.

Palmer, T. N., 1986: Influence of the Atlantic, Pacific, and Indian Ocean on Sahel rainfall. Nature, 322, 251-253, doi:10.1038/ $322251 \mathrm{a} 0$.

Preethi, B., T. P. Sabin, J. A. Adedoyin, and K. Ashok, 2015: Impacts of the ENSO Modoki and other tropical Indo-Pacific climate drivers on African rainfall. Sci. Rep., 5, 16653, doi:10.1038/srep16653.

Rodríguez-Fonseca, B., and Coauthors, 2011: Interannual and decadal SST-forced responses of the West African monsoon. Atmos. Sci. Lett., 12, 67-74, doi:10.1002/asl.308.

— African droughts: A review on the role of sea surface temperature anomalies. J. Climate, 28, 4034-4060, doi:10.1175/ JCLI-D-14-00130.1.

Rowell, D. P., 2003: The impact of Mediterranean SSTs on the Sahelian rainfall season. J. Climate, 16, 849-862, doi:10.1175/ 1520-0442(2003)016<0849:TIOMSO > 2.0.CO;2.

_ C. K. Folland, K. Maskell, and M. N. Ward, 1995: Variability of summer rainfall over tropical North Africa (1906-92): Observations and modeling. Quart. J. Roy. Meteor. Soc., 121, 669-674, doi:10.1002/qj.49712152311.

Schreck, C. J., and F. H. M. Semazzi, 2004: Variability of the recent climate of eastern Africa. Int. J. Climatol., 24, 681-701, doi:10.1002/joc.1019.

Segele, Z. T., M. B. Richman, L. M. Leslie, and P. J. Lamb, 2015: Seasonal-to-interannual variability of Ethiopia/Horn of Africa monsoon. Part II: Statistical multimodel ensemble rainfall predictions. J. Climate, 28, 3511-3536, doi:10.1175/ JCLI-D-14-00476.1.

Shongwe, M. E., G. J. van Oldenborgh, B. J. J. M. van den Hurk, B. de Boer, C. A. S. Coelho, and M. K. van Aalst, 2009: Projected changes in mean and extreme precipitation in Africa under global warming. Part I: Southern Africa. J. Climate, 22, 3819-3837, doi:10.1175/2009JCLI2317.1.
Smith, R., and Coauthors, 2010: The Parallel Ocean Program (POP) reference manual ocean component of the Community Climate System Model (CCSM) and Community Earth System Model (CESM). Rep. LAUR-01853, 141 pp. [Available online at www.cesm.ucar.edu/models/cesm1.0/pop2/doc/sci/ POPRefManual.pdf.]

Ummenhofer, C. C., A. Sen Gupta, M. H. England, and C. J. C. Reason, 2009: Contribution of Indian Ocean sea surface temperatures to enhanced East African rainfall. J. Climate, 22, 993-1013, doi:10.1175/2008JCLI2493.1.

UNEP/GRID-Arendal, 2007: People affected by natural disasters during the period 1971-2001. Accessed January 2017. [Available online at http://www.grida.no/resources/7422.]

Vizy, E. K., and K. H. Cook, 2001: Mechanisms by which Gulf of Guinea and eastern North Atlantic sea surface temperature anomalies can influence African rainfall. J. Climate, 14, 795-821, doi:10.1175/1520-0442(2001)014<0795:MBWGOG >2.0.CO;2. , and - 2012: Mid-twenty-first-century changes in extreme events over northern and tropical Africa. J. Climate, 25, 57485767, doi:10.1175/JCLI-D-11-00693.1.

Wang, F., Z. Liu, and M. Notaro, 2013: Extracting the dominant SST modes impacting North America's observed climate. J. Climate, 26, 5434-5452, doi:10.1175/JCLI-D-12-00583.1. , M. Notaro, Z. Liu, and G. Chen, 2014: Observed local and remote influences of vegetation on the atmosphere across North America using a model-validated statistical technique that first excludes oceanic forcings. J. Climate, 27, 362-382, doi:10.1175/JCLI-D-13-00080.1.

Wen, N., Z. Liu, Q. Liu, and C. Frankignoul, 2010: Observed atmospheric responses to global SST variability modes: A unified assessment using GEFA. J. Climate, 23, 1739-1759, doi:10.1175/2009JCLI3027.1.

WFP, 2017: Horn of Africa drought crisis situation report \#01, World Food Programme, 2 pp. [Available online at https:// www.wfp.org/Situation-Reports/Ethiopia.]

Yang, W., R. Seager, M. A. Cane, and B. Lyon, 2014: The East African long rains in observations and models. J. Climate, 27, 7185-7202, doi:10.1175/JCLI-D-13-00447.1.

$-, \ldots,-$, and -2015 : The rainfall annual cycle bias over East Africa in CMIP5 couple climate models. J. Climate, 28, 9789-9802, doi:10.1175/JCLI-D-15-0323.1.

Yin, L., R. Fu, Y. F. Zhang, P. A. Arias, D. N. Fernando, W. Li, K. Fernandes, and A. R. Bowerman, 2014: What controls the interannual variation of the wet season onsets over the Amazon? J. Geophys. Res. Atmos., 119, 2314-2328, doi:10.1002/ 2013JD021349.

Yu, Y., M. Notaro, Z. Liu, F. Wang, F. Alkolibi, E. Fadda, and F. Bakhrjy, 2015: Climatic controls of the interannual to decadal variability in Saudi Arabian dust activity: Towards the development of a seasonal dust prediction model. J. Geophys. Res. Atmos., 120, 1739-1758, doi:10.1002/2014JD022611.

Zhong, Y., and Z. Liu, 2008: A joint statistical and dynamical assessment of atmospheric response to North Pacific oceanic variability in CCSM3. J. Climate, 21, 6044-6051, doi:10.1175/ 2008JCLI2195.1.

- - and M. Notaro, 2011: A GEFA assessment of observed global ocean influence on U.S. precipitation variability: Attribution to regional SST variability modes. J. Climate, 24, 693-707, doi:10.1175/2010JCLI3663.1. 